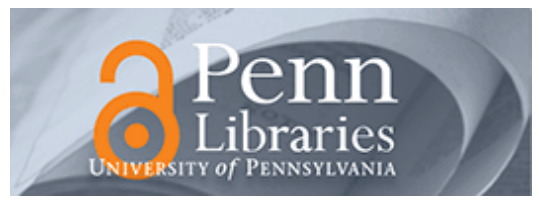

University of Pennsylvania

ScholarlyCommons

Real Estate Papers

Wharton Faculty Research

$1-2006$

\title{
Labour Pooling, Labour Poaching, and Spatial Clustering
}

Pierre-Philippe Combes

Gilles Duranton

University of Pennsylvania

Follow this and additional works at: https://repository.upenn.edu/real-estate_papers

Part of the Real Estate Commons

\section{Recommended Citation}

Combes, P., \& Duranton, G. (2006). Labour Pooling, Labour Poaching, and Spatial Clustering. Regional Science and Urban Economics, 36 (1), 1-28. http://dx.doi.org/10.1016/j.regsciurbeco.2005.06.003

This paper is posted at ScholarlyCommons. https://repository.upenn.edu/real-estate_papers/60

For more information, please contact repository@pobox.upenn.edu. 


\title{
Labour Pooling, Labour Poaching, and Spatial Clustering
}

\begin{abstract}
When firms cluster in the same local labour market, they face a trade-off between the benefits of labour pooling (i.e., access to workers whose knowledge help reduce costs) and the costs of labour poaching (i.e., loss of some key workers to competition and a higher wage bill to retain the others). We explore this tradeoff in a duopoly game. Depending on market size, on the degree of horizontal differentiation between goods, and on worker heterogeneity in terms of knowledge transfer cost, we characterise the strategic choices of firms regarding locations, wages, poaching and prices. Our results show that co-location, although it is always efficient in our framework, is not in general the non-cooperative equilibrium outcome.
\end{abstract}

\section{Keywords}

labour pooling, labour poaching, film clustering, agglomeration

Disciplines

Real Estate 


\title{
LABOR POOLING, LABOR POACHING, AND SPATIAL CluStering
}

March 2001

CERAS Working Paper 01-03

\author{
Pierre-Philippe COMBES \\ CNRS, CERAS and CEPR \\ 28, rue des Saints-Pères \\ 75007 Paris, France \\ combes@enpc.fr \\ http://www.enpc.fr/ceras/combes/
}

\author{
Gilles DURANTON \\ London School of Economics and CEPR \\ Houghton Street \\ London WC2A 2AE, UK \\ g.duranton@1se.ac.uk \\ http://cep.lse.ac.uk/ duranton/
}

\begin{abstract}
When firms cluster in the same local labor market, they face a tradeoff between the benefits of labor pooling (i.e., access to workers whose knowledge help reduce costs) and the costs of labor poaching (i.e., loss of some key workers to competition and the indirect effect of a higher wage bill to retain the others). We explore this tradeoff in a duopoly game. Depending on market size and on the degree of horizontal differentiation between products, we characterize the strategic choices of firms regarding locations, wages, poaching and prices. Our results show that co-location, although it is always efficient, is not in general the equilibrium outcome.
\end{abstract}

We thank seminar and conference participants, Bernard Caillaud, Francesco De Sinopoli, Laurent Linnemer, Jarle Møen, Jean Tirole, Kazuhiro Yamamoto, Yves Zenou and in particular Peter Neary for their remarks, comments and suggestions. This work was started when the first author was visiting the Centre for Economic Performance of the London School of Economics whose hospitality is gratefully acknowledged. 
"Breakaways of workers - especially the very able workers - from existing organizations promote the development of new work as well as the creation of new organizations. But breakaways are not good for the parent company; they undermine its efficiency. To the company or companies in control, one of the advantages of a company town is that breakaways are not feasible there. And in any settlement where breakaways are inhibited, by whatever means, the development rate must drop, although the efficiency of already well-established work is apt to climb." (Jacobs, 1969, p.97).

\section{INTRODUCTION}

Why do firms tend to cluster in some locations instead of spreading evenly over space? In his pioneering discussion of the question, Alfred Marshall (1890) argued that firms cluster to economize on the transport of goods, people and ideas. These three motives for economic agglomeration are also known as: availability of intermediate/final goods, labor market pooling, and technological spillovers, respectively.

Following Abdel-Rahman and Fujita (1990) in urban economics and Krugman (1991) in regional economics, a large fraction of the recent work on economic agglomeration focused on the first of the above arguments. If shipping manufactured goods is costly, firms prefer to locate where the market for final goods is larger in order to save on transport costs. This leads to a larger labor market, which in turn enlarges the market for final goods. In Abdel-Rahman and Fujita (1990), this agglomeration force is limited by the scarcity of urban land, so that increasing population in a given city increases crowding and eventually offsets the gains from concentration. In Krugman's benchmark, the same agglomeration force is limited by the cost of serving the immobile demand located in peripheral markets. This type of model has received a lot of attention in the recent past and we shall not discuss it further (see Ottaviano and Puga, 1998, for a survey of the regional literature and Duranton and Puga, 2000, for a review of its urban counterpart).

Turning to labor market pooling, the existing literature is much thinner. It tends overwhelmingly to favor labor market pooling as a strong motive for economic agglomeration and the formation of cities. The argument runs as follows. A larger pool of workers in an area makes it easier for firms to find workers with the characteristics they need. Conversely, workers are more likely to find a job suited to their skills in a larger labor market. In short, labor pooling improves the matching between firms and workers. The forces limiting urban growth and the concentration of workers are usually taken to be the diseconomies of scale associated with increasing city size (higher commuting costs, urban congestion, higher land rent). Helsley and Strange (1990) offer an elegant and sophisticated version of this argument.

Finally, localized technological spillovers are a popular motive for agglomeration. However, the argument is not as straightforward as it may seem. If knowledge can flow freely out of the firms, why are the effects of spillovers localized? To resolve this contradiction, Fujita and Ogawa (1982) propose a model with an information externality subject to distance decay. The distance decay aims to capture the frictions associated with the spatial propagation of information. But it remains unclear what these spatial frictions precisely are. The second criticism of the spillover argument is that spillovers "leave no paper trail by which they may be measured and tracked" (Krugman, 1991, p. 53). Consequently, nothing prevents the theorists from assuming whatever they like. Although subsequent empirical research showed 
that spillovers actually leave some paper trail through patent citation for instance and decrease with distance (Jaffe et al., 1993), the amount of evidence on localized spillovers to date is still very thin.

In this paper we wish to revisit these last two agglomeration motives. We start with the premise that distance acts as a barrier for workers' job mobility. The basic thrust of our argument is then to assume that workers have access to crucial knowledge about their own firms, be it about products, production methods, marketing or management. If we also (realistically) assume that this type of knowledge cannot all be patented and that exclusive labor contracts are not available, the clustering of firms on the same local labor market (i.e., labor market pooling) can lead to labor market poaching and the diffusion of knowledge. TSince knowledge is partly embodied in workers, flows of workers can be associated with flows of knowledge so that poaching workers is a way for firms to raise their productivity. 2. In turn, this has a knock-on effect on product market competition between firms. When choosing to locate close to their competitors, firms face a tradeoff between the benefits of labor market pooling and the costs of labor market poaching. The benefits of pooling rest with the opportunities for a firm to hire workers whose knowledge was gained in other firms and can be profitably adapted internally. The costs of poaching are twofold. Competitors can have access to the firm's own knowledge by poaching from its workforce. This makes them more competitive on the product market. Alternatively, this firm can reduce poaching by raising the wage of its strategic workers but this comes at the cost of a higher wage bill.

To explore this tradeoff more precisely and to show how and when the labor market at the local level can act as a conduit for spillovers, we propose a four-stage game between duopolistic firms producing differentiated goods. First, firms need to choose a location and set-up their production facility. Workers involved with a firm at this stage have access to some of its specific knowledge. In the second stage, firms commit to a wage for these "strategic" workers. When firms are located together, it is then possible in the third stage for a firm to poach workers from the other firm. This can be done by offering them a higher wage than they were promised. The knowledge of poached workers can then be transferred to their new employer. In the last stage price competition takes place.

Depending on market size and the degree of horizontal differentiation between products, we characterize the strategic choices of firms regarding locations, wages, poaching and prices for our duopoly game. Our results show that co-location, although it is always efficient, is not in general the equilibrium outcome. In particular, firms tend to separate when the conditions of perfect competition are approached. As rivalry intensifies, the incentives to raise the wage of their strategic workers increase while poaching decreases. This means a higher cost of co-location because of higher wages, as well as lower benefits of co-location

\footnotetext{
1 The assumption that workers' propensity to change jobs in the same local labor market is greater than their propensity to move between local labor markets, quite naturally justifies the localized aspect of spillovers so that this need not be justified by an exogenous decay function as in the earlier literature.

2 According to Arrow (1962, p. 615) "No amount of legal protection can make a thoroughly appropriable commodity of something as intangible as information" and then he adds that "mobility of personnel among firms provides a way of spreading information".
} 
because of smaller flows of workers and knowledge across firms. When the costs of poaching are higher than the benefits of pooling, firms locate separately. Thus, despite the advantages of labor market pooling, firms may choose strategically to locate in different local labor markets in order to avoid labor market poaching. Hence, the labor pooling argument for agglomeration is not as straightforward as envisioned in the previous literature. Further, this source of spillovers we propose here may be fairly attractive from an empirical point of view as the movement of workers between firms usually leaves some paper trail. Finally, this also implies that labor market pooling and spillovers can no longer be viewed as distinct motives for agglomeration since technological spillovers may travel through the labor market.

This paper relates to the small amount of literature in labor economics on workers' flows across firms. A first strand, following Rosen (1972), views occupational mobility as the result of optimal investment decisions made by workers over their life-cycle. In a competitive labor market, where different jobs tying together work and learning are available, younger workers optimally choose jobs that offer low wages but fast acquisition of general human capital. When reaching maturity, these workers recoup their investment by switching to occupations with less learning opportunities. In this type of model, more experienced workers get a higher wage because they have acquired more general human capital making them more productive.円Pakes and Nitzan (1983) propose an alternative two-period framework where a scientist needs to match with an entrepreneur to develop a project. At the end of the first period, the information about the project is disclosed to both parties. Then Pakes and Nitzan (1983) show that it is never profitable for the scientist to part from the entrepreneur and create a rival firm since the sum of the rents in a duopolistic market is lower than that of a monopoly, a joint-profit effect. The fundamental difference between this second type of model and the human capital approach is that more experienced workers get a higher wage, not because of higher productivity, but because defecting to a competitor could harm their employer. A very similar mechanism is at work in Motta et al. (2001) who study the decision of a single firm to export or to go multinational.

We clearly stand in this second tradition. Notwithstanding the spatial focus, there are two main differences with the Pakes and Nitzan (1983) approach. First we consider a continuum of workers and show that the joint-profit effect is not robust to this variation. The reason is that receiving a large fraction of a duopoly rent is better than a small fraction of a monopoly rent. This gives a strong incentive for workers to defect. The other major difference is that we consider a model of reciprocal poaching instead

\footnotetext{
3 There are examples of firms relocating some of their strategic facilities (R\&D centers, trial production plants, etc) away from famous specialized clusters. For instance, according to Jackson (1997, p. 138) Intel in the 1980s started to limit its workforce in Silicon Valley: "Nothing was more frustrating than spending months helping an operator to learn how to work a sensitive and unpredictable piece of machinery, only to see that same operator take a job down the street at National or Fairchild for a dollar more per hour.[...] Each time it built a new fab outside the Valley, [Intel] could feed off a fresh labor pool, with fewer competitors to lure its best people away".
} 
of a situation with an incumbent and an entrant. Such an assumption may be better suited to analyze the interactions between existing firms. The latter have the advantage of being empirically more easy to observe than potential entrants.

Last, our model also contributes to the large literature on strategic investments (see Tirole, 1988, chapter 8 , for a survey). Labor poaching is a form of strategic investment that allows a firm to lower its marginal cost before product market competition takes place. However, the cost of this investment is also endogenous and strategically determined in a previous stage by the other firm through its choice of wage. This wage decision can be viewed as a "counter-investment" since higher wages make poaching by the other firm more expensive. Even before that, firms can strategically decide not to enter this poaching game by locating on a separate local labor market.

The rest of the paper is as follows. In the next section, we discuss the empirical relevance of our main assumptions. In Section 3, we present a game in which firms compete both for each other's workers and on the product market. In Section 4, the game is solved for the prices, poaching, and wages decisions. We explore the location decision of firms and the welfare in Section 5. The last section contains some concluding remarks.

\section{WORKER FLOWS AND KNOWLEDGE FLOWS IN LOCAL LABOR MARKETS}

Before presenting the details of the model we wish to empirically substantiate its two main components.

Our first stylized fact is that workers often move between firms and that these flows are mostly local. Direct evidence about this can be obtained from French employment data. The data, extracted from the 1996 and 1997 Déclarations Annuelles de Données Sociales (DADS) database of the Institut National de la Statistique et des Etudes Economiques (INSEE), contains the employment area, the occupation and the sector for their main job of all French employees that were born in October in even years. Continental France is fully covered by 341 employment areas, whose boundaries are defined on the basis of daily commuting patterns. PThe firms are classified by sector according to level 36 of the Nomenclature d'Activités Française of INSEE. Occupations are classified according to level 37 of Catégories SocioProfessionelles of INSEE. Among all occupations we selected only 6 of them: Scientists, Executives (commercial and administration), Engineers, Technical Personnel, Foremen, Specialized manufacturing workers. These six groups, we believe, are those whose mobility across firms is most likely to be

\footnotetext{
${ }^{4}$ Recent developments in this strand of research include Jovanovic and Nyarko (1995) and Franco and Filson (2000). The former propose a theory of the diffusion of knowledge between managers and employees, whereas the latter are concerned by breakaways of employees to create their own firm.

${ }^{5}$ Given that within Greater Paris (Ile-de-France), changes of job do not usually involve workers changing residence and that commuting across employment areas is easy, we decided to lump together the 26 employment areas forming Greater Paris.
} 
associated with transfers of knowledge.

We first computed the intra-occupation turnover rate, that is, for each occupation, the fraction of workers who changed employer among those employed in the same sector during the two years. Dext, conditional on workers having a different main employer in 1996 and in 1997, we computed the fraction of workers in each occupation that remained in the same sector and the same employment area, the fraction that remained in the same employment area but changed sector and the fraction that remained in the same sector but changed employment area. The results are summarized in Table 1 .

\begin{tabular}{|l|c|l|l|l|l|l|r|}
\hline & Scientists & Executives & Engineers & Technicians & Foremen & $\begin{array}{l}\text { Skilled } \\
\text { workers }\end{array}$ & All \\
\hline $\begin{array}{l}\text { Intra-occupation } \\
\text { turnover rate }\end{array}$ & $9.6 \%$ & $10.1 \%$ & $11.7 \%$ & $8.7 \%$ & $8.2 \%$ & $9.9 \%$ & $\mathbf{9 . 8 \%}$ \\
\hline \hline $\begin{array}{l}\text { Same area, same } \\
\text { sector }\end{array}$ & $43.4 \%$ & $39.2 \%$ & $46.9 \%$ & $42.7 \%$ & $48.7 \%$ & $43.1 \%$ & $\mathbf{4 3 . 4 \%}$ \\
\hline $\begin{array}{l}\text { Same area, } \\
\text { different sector }\end{array}$ & $16.2 \%$ & $32.7 \%$ & $28.9 \%$ & $33.0 \%$ & $25.7 \%$ & $32.3 \%$ & $\mathbf{3 0 . 4 \%}$ \\
\hline $\begin{array}{l}\text { Different area, } \\
\text { same sector }\end{array}$ & $30.3 \%$ & $13.0 \%$ & $9.6 \%$ & $8.7 \%$ & $12.8 \%$ & $8.9 \%$ & $\mathbf{1 1 . 4 \%}$ \\
\hline $\begin{array}{l}\text { Different area, } \\
\text { Different sector }\end{array}$ & $10.1 \%$ & $15.1 \%$ & $14.7 \%$ & $15.6 \%$ & $12.8 \%$ & $15.7 \%$ & $\mathbf{1 4 . 8 \%}$ \\
\hline
\end{tabular}

Table 1

Among French workers who remain in the same occupation, around one in ten changes employer every year. Regarding sectoral and geographical mobility, the results are remarkably consistent across occupations except for scientists, who are slightly more mobile. Around $45 \%$ of workers that change jobs remain in the same employment area and in the same sector. Another 30\% remain in the same employment area but in a different sector. In other words, when they change employer, around $75 \%$ of skilled French workers remain in the same employment area. The levels of geographical mobility implied by these figures are very low given that the average French employment area is equivalent to a circle of radius $23 \mathrm{~km}$.

The French case is not exceptional. At a slightly larger level of aggregation and for all workers, the literature on internal migrations systematically reports low gross inter-regional flows (see Greenwood, 1997, for a survey). Gross inter-regional flows of less than $2 \%$ a year seem to be the norm in Europe.

Our second major assumption is that workers flows are also knowledge flows. Many case-studies strongly support the idea that workers, when they change employers, come with knowledge about their former employer and that this knowledge can be profitably used by their new employer. Saxenian [1994] made a convincing case that the incessant turnover of skilled labor between firms in the Silicon Valley was closely linked to the area's success. In this paper we would like to discuss briefly another highly revealing cluster, the British Motor Valley, which has been recently investigated by Henry and Pinch

\footnotetext{
${ }^{6}$ Given the focus of our model, , we only consider the population of workers who have been employed in the same occupation over two consecutive years. This is likely to yield lower turnover rates than those in the literature, which are typically computed relative to the population in the labor force at large. See Davis and Haltiwanger (1998) for the US and Burda and Wyplosz (1994) for Europe.
} 
(1997a, 1997b) and Pinch et al. (1997).

The British motor sport industry clusters heavily in the Thames Valley around London where it directly employs over 50,000 workers, most of them highly skilled. It is by far the leading motor sport industry at the world level. It produces sport cars in the upper end of the segment: touring cars, racing cars, Formula One cars, and even Indy cars, although all the Indy car races take place in the US. In these markets, the dominance of the British Motor Valley is nearly absolute. If one breaks down the making of a Formula One into four main parts (design, base, chassis and engine), 9 teams out of 14 had three or four of these parts made in the British Motor Valley in 1997. Only one team had no presence at all.

As Henry and Pinch (1997a, p. 14) observe "the history of Formula One is full of radical innovations that spread throughout the sport. The diffusion is often rapid because it is difficult to keep these innovations secret for long. One reason for the rapid diffusion of ideas is the fact that the drivers, designers and engineers move from team to team, taking with them considerable knowledge of how things are done in rival teams". Elsewhere, Henry and Pinch (1997b, p. 5) also note that "knowledge is spread by the rapid and continual transfer of staff between companies within the industry. Our mapping of the career histories of 100 designers/engineers in the industry revealed a move, on average every 3.7 years and a total of 8 moves in the career in the industry. [...] As personnel move, they bring with them knowledge and ideas about how things are done in other teams, helping to raise the level of knowledge throughout the industry. Whilst this may not change the pecking order within the industry, this 'churning' of personnel raises the knowledge base of the industry as a whole." Finally by using interviews, Pinch et al. (1997) show that this continual churning of staff is recognized by key people in the industry to be enormously beneficial for the industry as a whole as well as for the individuals concerned if not always by teams loosing key workers."[

Although hard evidence regarding these issues is scarce because of the difficulties associated with measuring these phenomena, we believe that these case-studies are representative of a wider trend where workers flows generate flows of knowledge across firms.

\section{THE MODEL}

Consider a partial equilibrium model with two differentiated goods, each produced by a different firm. Let 1 and 2 denote these two firms, which sell their goods in a common and perfectly integrated market. We also assume two different locations $I$ and $J$, each constituting a separate local labor market. These labor markets are completely segmented with workers being immobile between them. In each labor market, there is an infinite supply of ex-ante homogenous labor at a wage $W$. 
The two firms play a four-stage game.

\section{STAGE 1 - LOCATION.}

Each firm choose a location, $I$ or $J$, where to produce its goods. We speak of co-location whenever both firms locate either in $I$ or $J$. After their location decision, firms must hire an exogenous quantity $\Lambda$ of workers. These workers are referred to as strategic workers. Hiring those workers is necessary for the firms to set-up their production facilities. Without loss of generality, we can assume this is done at no direct (wage) cost. But, when setting up production facilities, workers acquire part of the internal knowledge of the firm. We assume firms cannot charge workers for this knowledge. PNeither can this knowledge be patented. Finally, exclusive long-term labor contracts are not available.

This stage can be thought of as the history of the firms. When it ends, firms are ready to operate in their location. They are also loaded with strategic workers who have access to their specific knowledge.

STAGE 2 - WAGE.

In view of the production stage, each firm commits to a wage $W+\omega_{j}(j=1,2)$ for its own strategic workers. This wage is paid only if the worker works for the firm at Stage 4. (In what follows, the wage premium, $\omega_{j}$, is referred to as the strategic wage.) The promise of a higher future wage is the only way a firm can protect itself from poaching when firms co-locate.P

\section{STAGE 3 - LABOR POACHING.}

Depending on what the firms played in Stage 1, two cases must be distinguished.

- When both firms are in the same location, they can poach on each other's strategic labor. Firm $i$, by proposing a wage, $W+w_{i}$, can hire as many of firm $j$ 's strategic workers as it likes provided it offers them a wage higher than that promised by the other firm: $W+w_{i} \geq W+\omega_{j}$.10 When it poaches $\lambda_{i}$ strategic workers with $0 \leq \lambda_{i} \leq \Lambda$ from the other firm, firm $i$ can use their knowledge to reduce its own

\footnotetext{
${ }^{7}$ See also En Route F1 (November 1999, page 44): "On the technical side, a driver who has decided to leave will be stopped from doing any private testing. Indeed, teams will wait until the end of the season before testing anything new that is to appear on the car the following year. There is no question of the driver who is leaving knowing the least details of how anything works."

8 Allowing firms to charge strategic workers at the beginning of Stage 2 would just impact on the outcome of Stage 1 by neutralizing effects on wages at this stage only. By a straightforward backward induction argument, the other effects would remain the same. We believe that it is more realistic to proceed as we do.

${ }^{9}$ Most of the real world mechanisms used by firms to keep their workforce use delayed payments (stock option, seniority system, etc). The alternative is to write restrictive labor contracts preventing defection to competitors. Such 'restrictive covenants' must however be reasonable in the eyes of the law. Furthermore the courts in most countries are protective of an employee's freedom to continue to sell his or her services after finishing employment in the face of an ex-employer seeking to restrict that liberty.

${ }^{10} \mathrm{We}$ assume a sequential (and reciprocal) auction process for strategic workers. The poached firm decides on a strategic wage first. The poaching firm then decides on a quantity. Note that the poacher realistically benefits from a second mover advantage. But, it must also be noted that the poached firm sets its second period wage forming rational expectations about the poacher's behavior at Stage 3. Alternative auctioning processes on strategic workers are left for future work.
} 
costs. For simplicity, there is no direct cost for firm $j$ when it loses $\lambda_{i}$ strategic workers 11 On the other hand, we assume that adapting the knowledge embodied in these $\lambda_{i}$ workers is costly for firm $i$.

- When firms are not in the same location, poaching is impossible because of the spatial immobility of labor.

\section{StAgE 4 - PRICE.}

Each firm hires its non-strategic labor, $l_{i}$, and price competition in the common market takes place between the two firms.

Let us now present the details of the model. The utility function of the representative consumer is quasilinear and quadratic:

$$
U\left(q_{1}, q_{2}, M\right)=(1+\alpha)\left(q_{1}+q_{2}\right)-\beta q_{1} q_{2}-\frac{1}{2}\left(q_{1}^{2}+q_{2}^{2}\right)+M
$$

where $q_{i}$ is the consumption of the good produced by firm $i, M$ is a homogeneous good which is used as numéraire, $\alpha>0$ and $0 \leq \beta<1$. Maximizing the utility function in (1), subject to the budget constraint $M+p_{1} q_{1}+p_{2} q_{2} \leq R$ with $R$ the income, leads to the following linear demand functions:

$q_{i}=\frac{1+\alpha}{1+\beta}+\frac{\beta}{1-\beta^{2}} p_{j}-\frac{1}{1-\beta^{2}} p_{i}, \quad i=1,2 \quad i \neq j$

The parameter $\alpha$ can be interpreted as reflecting the market size or strength of the demand, whereas $\beta$ is an inverse-index for the degree of differentiation between the two goods. In the particular case where $\beta=0$, firms are in a monopoly position on their markets, whereas the limit case $\beta=1$ is equivalent to Bertrand competition with homogenous goods 12 All the results derived below depend only on these two parameters. The concavity of the utility function guarantees that the demand derived in equation (2) defines a maximum.

Turning to production, assume a constant labor requirement per unit:

$L_{i}=c_{i} q_{i}$

where $c_{i}$ is the labor requirement per unit (or unit labor requirement) and $L_{i}$ is firm $i$ 's total labor force. Three different kinds of workers must be distinguished: (i) remaining (or unpoached) strategic workers in quantity $\left(\Lambda-\lambda_{j}\right)$, (ii) workers poached from firm $j$ in quantity $\lambda_{i}$, and (iii) non-strategic workers in quantity $l_{i}$. Consequently total employment in firm $i$ is:

$L_{i}=\left(\Lambda-\lambda_{j}\right)+\lambda_{i}+l_{i}$.

\footnotetext{
${ }^{11}$ Having such a cost would only reinforce our results.
} 
The knowledge of poached workers can be used to reduce the firm's unit labor requirement. Unit labor requirement reduction decreases with the number of poached workers:

$$
c_{i}=\bar{c}-a \lambda_{i},
$$

with $\bar{c}$ the initial level of marginal cost and $a$ an index of knowledge transferability. For consistency we assume $\bar{c} \geq a \Lambda$, so that firms always face positive unit labor requirements. For demand to be positive when price is equal to marginal cost, we also impose $\bar{c} \leq(\alpha+1) / W$.

We assume that transferring knowledge is costly and rising in the amount of knowledge to be transferred. This cost also depends on the degree of differentiation between products. Competing forces may be at play here. On the one hand, when products are close substitutes, they may use very similar technologies so that the potential to learn from each other may be low. On the other hand, very differentiated goods may use very different technologies. This may limit how much firms can adapt from each other. The cost of transferring knowledge takes the following form:

Cost of transferring knowledge $=T(\beta) \lambda_{i}^{2}$.

The quadratic term in equation (6) implies that there are decreasing returns to scale in the poaching technology, since a unit reduction in labor requirement is more costly when many workers have already been poached and it raises with $\left.\lambda_{i}\right]^{13}$ This cost, $T(\beta)$, is allowed to depend on the degree of differentiation between the products and can be decreasing as well as increasing in $\beta$. As we shall see, some of our results depend on the shape of $T($.$) .$

The general resolution of the model implies that the proportions of poached workers, the profits when the two firms locate in the same labor market relative to when the firms locate separately, as well as the relative prices and strategic wages, are function only of $\beta, T(\beta) /(a W \Lambda)^{2}$ and $(1+\alpha-\bar{c} W) /(a W \Lambda)$. Consequently, without loss of generality, we can to normalize $\Lambda, \bar{c}, a$, and $W$ to unity. 14 Thus, the rest of the analysis considers only the function $T($.$) and two parameters: \alpha$ reflecting market size and $\beta$ the inverse degree of differentiation between products. After these normalizations, equations (3) to (6) yield:

$$
\pi_{i}=p_{i} q_{i}-\left(1+\omega_{i}\right)\left(1-\lambda_{j}\right)-\left(1+w_{i}\right) \lambda_{i}-l_{i}-T(\beta) \lambda_{i}^{2} .
$$

In this expression, the first term is the total revenue, the second is the cost of retaining strategic workers,

\footnotetext{
12 See Ottaviano and Thisse (1999) for further comments on these preferences.

13 This assumption of quadratic costs together with linear demand is standard in the strategic R\&D literature. See Leahy and Neary (1997) for more on this.

14 The derivation of this result is omitted here. The normalizations of the number of strategic workers and initial costs are just choices of units for inputs and outputs. The normalization of $a$ amounts to normalizing minimum marginal costs to zero. Together with the normalization of the wage, this amounts to re-scaling both firms' profits and consumer's utility.
} 
the third is the cost of poaching workers from the other firm, the fourth is the cost of non-strategic workers, and the fifth is the cost of transferring knowledge.

\section{PRICES, POACHING AND WAGES UNDER CO-LOCATION}

Throughout we assume that the cost of transferring knowledge, $T(\beta)$, is sufficiently large. When this cost is low, a firm can rely only on high wages to retain its workers. This may be very costly. In this case, it can be worthwhile for this firm to deviate by undercuting wages and let the other firm poach all its workers. The absence of such a profitable deviation is guaranteed by the following sufficient condition for the existence (SCE) of sub-game perfect Nash-equilibria in pure strategies:15

$T(\beta)>\frac{5-\beta}{20(1-\beta)}$

For the sake of clarity, condition (SCE) is assumed to hold in what follows. The behavior of the model when (SCE) does not hold is discussed in Section IV.4. The current section solves for the last three stages of the game (wages, poaching and prices). The location stage is analyzed in Section V together with welfare. Two specific examples are also developed in the same section for illustrative purpose.

\section{IV.1 Stage 4: PRICE COMPETITION}

Firm $i$ maximizes its profit with respect to its price, subject to demand and feasibility constraints. At this stage, it takes as given the pricing behavior of the other firm, the number of poached workers, the unit labor requirement, and the strategic wages. Its program is thus:

$$
\begin{gathered}
\underset{p_{i}}{\operatorname{Max}} p_{i} q_{i}-l_{i}-\left(1-\lambda_{j}\right)\left(1+\omega_{i}\right)-\lambda_{i}\left(1+w_{i}\right)-T(\beta) \lambda_{i}^{2}, \\
\text { with }\left\{\begin{array}{l}
q_{i}=\frac{\alpha+1}{1+\beta}+\frac{\beta}{1-\beta^{2}} p_{j}-\frac{1}{1-\beta^{2}} p_{i}, \\
l_{i}=c_{i} q_{i}-\left(1-\lambda_{j}\right)-\lambda_{i} .
\end{array}\right.
\end{gathered}
$$

After simplification, the first-order conditions of program (8) imply:

$$
\begin{aligned}
& p_{i}=\frac{1-\beta}{2-\beta}(1+\alpha)+\frac{2 c_{i}+\beta c_{j}}{(2-\beta)(2+\beta)}, \\
& q_{i}=\frac{1+\alpha}{(2-\beta)(1+\beta)}+\frac{\beta c_{j}-\left(2-\beta^{2}\right) c_{i}}{(2-\beta)(2+\beta)(1+\beta)(1-\beta)}, \\
& l_{i}=c_{i} q_{i}-\lambda_{i}-\left(1-\lambda_{j}\right) .
\end{aligned}
$$

\footnotetext{
15 See the proof of Proposition 2 in Appendix 2.
} 
It can be easily checked from the second-order conditions that these three equations define a sub-game perfect Nash-equilibrium. Inserting equations (9) to (11) into the profit function (7) yields:

$\pi_{i}=\Pi_{i}\left(c_{i}, c_{j}\right)-\omega_{i}\left(1-\lambda_{j}\right)-w_{i} \lambda_{i}-T(\beta) \lambda_{i}^{2}$,

with $\Pi_{i}\left(c_{i}, c_{j}\right)=\frac{\left[(1+\alpha)(2+\beta)(1-\beta)+\beta c_{j}-\left(2-\beta^{2}\right) c_{i}\right]^{2}}{(2-\beta)^{2}(2+\beta)^{2}(1-\beta)(1+\beta)}$.

The interpretation of equation (12) is straightforward. The first term is the revenue associated with the unit labor requirements $c_{i}$ and $c_{j}$. The second term is the cost of retaining strategic workers. The third term is the cost of poaching and finally the last term is the cost of transferring knowledge.

\section{IV.2 Stage 3: PoACHING DeCision}

When the firms co-locate, poaching may take place. In order to poach workers, firm $i$ must offer a strategic wage above that of firm $j$. Obviously, it will set $w_{i}=\omega_{j}$ regardless of the number of workers it poaches. Inserting this and equation (5) into equation (12) implies the following program:

$$
\operatorname{Max}_{0 \leq \lambda_{i} \leq 1} R_{i}\left(\lambda_{i}, \lambda_{j}\right)-\omega_{i}\left(1-\lambda_{j}\right)-\omega_{j} \lambda_{i}-T(\beta) \lambda_{i}^{2}
$$

with $R_{i}\left(\lambda_{i}, \lambda_{j}\right) \equiv A\left[B\left(\alpha+\lambda_{i}\right)+\beta\left(\lambda_{i}-\lambda_{j}\right)\right]^{2}, A \equiv \frac{1}{\left(4-\beta^{2}\right)^{2}\left(1-\beta^{2}\right)}$ and $B \equiv 2-\beta-\beta^{2}$.

The revenue $R_{i}\left(\lambda_{i}, \lambda_{j}\right)$ increases with the size of the demand $\alpha$ and decreases with the substitutability between products, $\beta$. It also increases with the number of poached workers, $\lambda_{i}$, since poaching leads to a reduction in unit labor requirement. Because it lowers costs, poaching leads to lower prices. This raises both total sales and the firm's market share. Competition in the final good market also implies that the firm's revenue declines with poaching by the other firm, $\lambda_{j}$.

From the first-order condition of program (14), $\partial R_{i} / \partial \lambda_{i}-\omega_{j}-2 T(\beta) \lambda_{i}=0$, it is possible to define the interior best-response in poaching:

$$
\hat{\lambda}\left(\lambda_{j}, \omega_{i}, \omega_{j}\right) \equiv \frac{1}{F}\left(\frac{B D \alpha}{\beta}-D \lambda_{j}-\frac{\omega_{j}}{2}\right)
$$

with: $D \equiv \frac{\beta\left(2-\beta^{2}\right)}{\left(4-\beta^{2}\right)^{2}\left(1-\beta^{2}\right)}=\beta A(B+\beta)$ and $F \equiv T(\beta)-\frac{\left(2-\beta^{2}\right)^{2}}{\left(4-\beta^{2}\right)^{2}\left(1-\beta^{2}\right)}=T(\beta)-A(B+\beta)^{2}$. 
Turning to the second-order conditions, it can be noted that $\partial^{2} \pi_{i} / \partial \lambda_{i}^{2}=-2 F 16$ It can be verified that if condition (SCE) is satisfied then $F>0$ for $\beta \in[0,1]$, so that the second-order conditions for this stage are satisfied. Following directly from (14), we can now write Lemma 1:

Lemma 1. Under (SCE) and co-location, firm i's best response at Stage 3 is:

- $\lambda_{i}^{B R}\left(\lambda_{j}, \omega_{i}, \omega_{j}\right)=1$,

$$
\begin{aligned}
& \text { if } \lambda_{j} \leq-\frac{F}{D}+\alpha \frac{B}{\beta}-\frac{\omega_{j}}{2 D}, \\
& \text { if }-\frac{F}{D}+\alpha \frac{B}{\beta}-\frac{\omega_{j}}{2 D}<\lambda_{j}<\alpha \frac{B}{\beta}-\frac{\omega_{j}}{2 D}, \\
& \text { if } \alpha \frac{B}{\beta}-\frac{\omega_{j}}{2 D} \leq \lambda_{j} .
\end{aligned}
$$$$
\text { - } \lambda_{i}^{B R}\left(\lambda_{j}, \omega_{i}, \omega_{j}\right)=\hat{\lambda}\left(\lambda_{j}, \omega_{i}, \omega_{j}\right) \text {, }
$$

- $\lambda_{i}^{B R}\left(\lambda_{j}, \omega_{i}, \omega_{j}\right)=0$,

As the best-response functions for each player are in three parts to account for corner solutions in the poaching decision, nine regions must be considered for Stage 3 (but only six when taking pairs of symmetric configurations into account). These regions are represented in Figure 1. ${ }^{[7}$

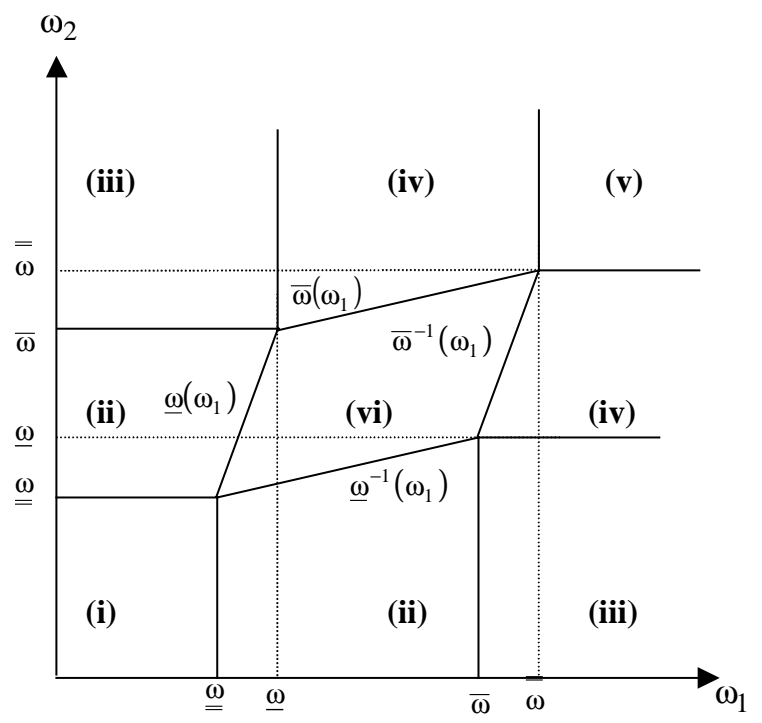

Figure 1.

More precisely, these regions are defined by:

- Region (i): $\omega_{1} \leq \underline{\underline{\omega}}$ and $\omega_{2} \leq \underline{\underline{\omega}}, \quad \cdot$ Region (ii): $\underline{\omega}\left(\omega_{i}\right) \leq \omega_{j}$ and $\underline{\underline{\omega}}<\omega_{j} \leq \bar{\omega}$,

- Region (iii): $\omega_{i} \leq \underline{\omega}$ and $\bar{\omega}<\omega_{j}, \quad \cdot R e g i o n(i v): \underline{\omega}<\omega_{i}<\overline{\bar{\omega}}$ and $\bar{\omega}\left(\omega_{i}\right)<\omega_{j}$,

- Region (v): $\overline{\bar{\omega}} \leq \omega_{1}$ and $\overline{\bar{\omega}} \leq \omega_{2}, \quad \cdot$ Region (vi): $\bar{\omega}^{-1}\left(\omega_{1}\right) \leq \omega_{2}<\underline{\omega}\left(\omega_{1}\right)$ and $\underline{\omega}^{-1}\left(\omega_{1}\right)<\omega_{2} \leq \bar{\omega}\left(\omega_{1}\right)$, where: $\quad \underline{\underline{\omega}} \equiv 2(B D \alpha / \beta-F-D), \quad \underline{\omega} \equiv 2(B D \alpha / \beta-F), \quad \bar{\omega} \equiv 2 D(B \alpha / \beta-1), \quad \bar{\omega} \equiv 2 B D \alpha / \beta$,

\footnotetext{
16 The shorthand notations $A, B, D$ and $F$ are only functions of $\beta$ and $T(\beta)$. They allow us to reduce drastically the length of the expressions below.

${ }^{17}$ Figure 1 is drawn assuming $\stackrel{\omega}{=}>0$, which is not necessarily the case.
} 
$\underline{\omega}\left(\omega_{i}\right) \equiv \frac{F}{D} \omega_{i}-2 \frac{F-D}{D}\left(\frac{B D}{\beta} \alpha-F-D\right)$, and $\bar{\omega}\left(\omega_{i}\right) \equiv \frac{D}{F} \omega_{i}+2 \frac{F-D}{F} \frac{B D}{\beta} \alpha$.

It is also useful to denote the intersection of the interior best-responses given in Lemma 1 by:

$\hat{\lambda}\left(\omega_{i}, \omega_{j}\right) \equiv \frac{1}{F+D}\left(\frac{B D}{\beta} \alpha+\frac{D \omega_{i}-F \omega_{j}}{2(F-D)}\right)$

as well as the semi-interior intersections, when $\lambda_{j}=1$ and $\lambda_{j}=0$ respectively:

$\underline{\lambda}\left(\omega_{j}\right) \equiv \frac{1}{F}\left(\frac{B D}{\beta} \alpha-D-\frac{\omega_{j}}{2}\right)$ and $\bar{\lambda}\left(\omega_{j}\right) \equiv \frac{1}{F}\left(\frac{B D}{\beta} \alpha-\frac{\omega_{j}}{2}\right)$.

Simple calculations then imply:

Lemma 2. Under (SCE) and co-location, the sub-game equilibria for each region at Stage 3 are:

- $\lambda_{1}^{*}\left(\omega_{1}, \omega_{2}\right)=\lambda_{2}^{*}\left(\omega_{2}, \omega_{1}\right)=1$ in region $(i)$,

- $\lambda_{i}^{*}\left(\omega_{i}, \omega_{j}\right)=\underline{\lambda}\left(\omega_{j}\right)$ and $\lambda_{j}^{*}\left(\omega_{j}, \omega_{i}\right)=1$ in region (ii),

- $\lambda_{i}^{*}\left(\omega_{i}, \omega_{j}\right)=0$ and $\lambda_{j}^{*}\left(\omega_{j}, \omega_{i}\right)=1$ in region (iii),

- $\lambda_{i}^{*}\left(\omega_{i}, \omega_{j}\right)=0$ and $\lambda_{j}^{*}\left(\omega_{j}, \omega_{i}\right)=\bar{\lambda}\left(\omega_{i}\right)$ in region (iv),

- $\lambda_{1}^{*}\left(\omega_{1}, \omega_{2}\right)=\lambda_{2}^{*}\left(\omega_{2}, \omega_{1}\right)=0$ in region $(v)$,

- $\lambda_{1}^{*}\left(\omega_{1}, \omega_{2}\right)=\hat{\lambda}\left(\omega_{1}, \omega_{2}\right)$ and $\lambda_{2}^{*}\left(\omega_{2}, \omega_{1}\right)=\hat{\lambda}\left(\omega_{2}, \omega_{1}\right)$ in region (vi).

This lemma can be summarized by Figure 2 .

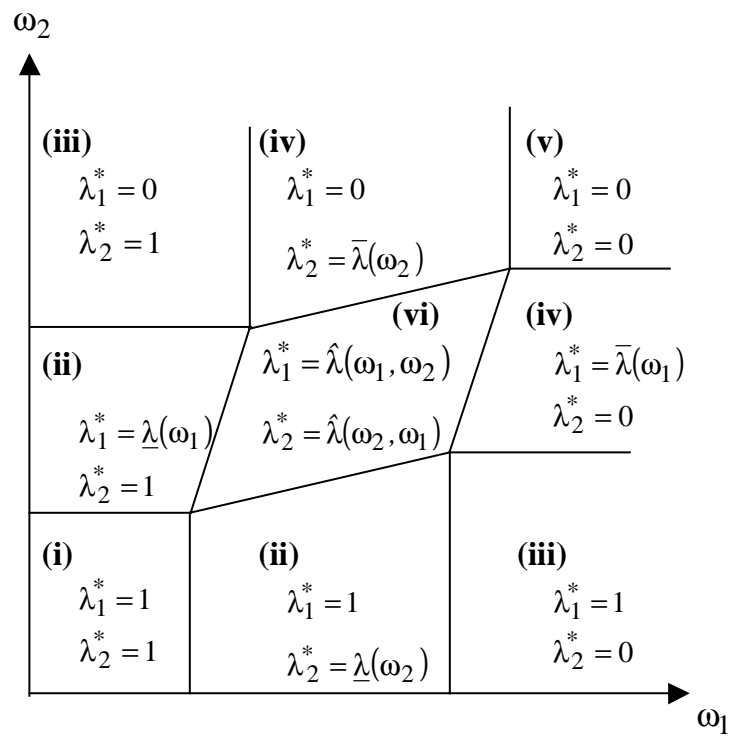

Figure 2.

To gain more insights, it is possible to look more precisely at the comparative statics of the poaching decision. 


\section{Proposition 1. Under (SCE) and co-location, in the poaching sub-game equilibrium, poaching}

- increases with the firm's own strategic wage, $\partial \lambda_{i}^{*}\left(\omega_{i}, \omega_{j}\right) / \partial \omega_{i} \geq 0$,

- decreases with the rival's strategic wage, $\partial \lambda_{i}^{*}\left(\omega_{i}, \omega_{j}\right) / \partial \omega_{j} \leq 0$,

- increases with demand, $\partial \lambda_{i}^{*}\left(\omega_{i}, \omega_{j}\right) / \partial \alpha \geq 0$,

- decreases with the substitutability between products, $\partial \lambda_{i}^{*}\left(\omega_{i}, \omega_{j}\right) / \partial \beta \leq 0$, for a symmetric equilibrium, unless the cost of knowledge transmission sharply decreases with $\beta$.

See Appendix 1 for a proof.

From program (14), the marginal incentive for firm $i$ to increase its poaching on firm $j$ 's labor force is $\partial R_{i} / \partial \lambda_{i}-\omega_{j}-2 T(\beta) \lambda_{i}$. This quantity decreases with $\omega_{j}$ and $\lambda_{j} 18$, whereas it does not depend on the firm's own wage. As a consequence, firm i's interior best-response for poaching (equation 16 and Lemma 1) declines with $\omega_{j}$ and $\lambda_{j}$ and is independent from $\omega_{i}$. The intuitions are the following. An increase in strategic wage by the other firm makes a reduction in unit labor requirement more expensive and this reduces best-response poaching. The effect of poaching by the other firm is more subtle. An increase in $\lambda_{j}$ implies an increase in firm $i$ 's relative marginal costs, which, in a price competition game, lowers its incentives to reduce them. In other words, the numbers of poached workers in the two firms are strategic substitutes. As regards own strategic wages, best-response poaching does not depend on them since the firm takes poaching by its rival as given. However, own wages impact on poaching in the subgame equilibrium through indirect effects. A higher $\omega_{i}$ reduces $\lambda_{j}$ which in turn increases firm $i$ 's poaching because of strategic substitutability.

The incentive to increase poaching also increases with $\alpha$ since a stronger demand increases the pay-off to lower marginal costs $\square$ Thus, best-response poaching also increases with demand through a gross profit effect. In equilibrium a higher demand also increases poaching by the other firm. In combination with strategic substitutability, this decreases the incentive to poach. However, straightforward calculations from Lemma 2 show that the direct effect dominates so that poaching increases with $\alpha$ in the sub-game equilibrium.

The effect of the degree of differentiation on the incentive to poach is ambiguous. First, when products become closer substitutes, firms have less incentive to reduce their relative marginal costs and thus to

$$
\begin{gathered}
18 \frac{\partial^{2} R_{i}}{\partial \lambda_{i} \partial \lambda_{j}}<0 . \\
19 \frac{\partial^{2} R_{i}}{\partial \lambda_{i} \partial \alpha}>0 .
\end{gathered}
$$


poach. When $\beta$ increases, differences in marginal costs translate into smaller differences in profits.20 This is a rivalry effect whereby competition is fiercer and profits lower. This effect of increased rivalry is reinforced by the cost of transferring knowledge when $T^{\prime}(\beta)>0$. In this case, as products are less differentiated, knowledge becomes more difficult to transfer between firms so that the incentive to poach is even weaker. By contrast, when $T^{\prime}(\beta)<0$, a larger $\beta$ makes it easier for firms to achieve a unit reduction in marginal costs and thus favors poaching. This second effects dominates only when $T($.) decreases sufficiently sharply. These direct effects determine the best-responses (equation 16 and Lemma 1) comparative statics. Some indirect equilibrium effects are also present as $\beta$ symmetrically impacts on the incentive of the other firm to poach. Because of strategic substitutability, these indirect effects go against the direct ones. However, in equilibrium, the direct effects of $\beta$ dominate the indirect effects working through $\lambda_{j}$, as stated in the last item of Proposition 1.

\section{IV.3 StAge 2: SETting WAGES FOR STRATEgIC WORKERS}

At this stage, the firms may use the wage of their strategic workers to prevent poaching. In the strategic wage sub-game, the firm's program is:

$$
\operatorname{Max}_{\omega_{i} \geq 0} R_{i}\left(\lambda_{i}^{*}\left(\omega_{i}, \omega_{j}\right), \lambda_{j}^{*}\left(\omega_{j}, \omega_{i}\right)\right)-\omega_{i}\left(1-\lambda_{j}^{*}\left(\omega_{j}, \omega_{i}\right)\right)-\omega_{j} \lambda_{i}^{*}\left(\omega_{i}, \omega_{j}\right)-T(\beta) \lambda_{i}^{* 2}\left(\omega_{i}, \omega_{j}\right)
$$

where $\lambda_{i}^{*}\left(\omega_{i}, \omega_{j}\right)$ and $\lambda_{j}^{*}\left(\omega_{j}, \omega_{i}\right)$ are given in Lemma 2 .

Using the envelop theorem, the first-order condition reduces to:

$$
\frac{\partial R_{i}}{\partial \lambda_{j}^{*}} \frac{\partial \lambda_{j}^{*}}{\partial \omega_{i}}-\left(\left(1-\lambda_{j}^{*}\right)-\frac{\partial \lambda_{j}^{*}}{\partial \omega_{i}} \omega_{i}=0\right.
$$

The first term in equation (21) is the marginal gain of increasing $\omega_{i}$. It is the product of two negative partial derivatives and is thus positive. A higher $\omega_{i}$ leads to less poaching by the other firm which increases revenue because of lower relative costs. As indicated by the last two negative terms in brackets in equation (21), a higher $\omega_{i}$ also raises costs by making retained workers more expensive and increasing their number. Note that the strategic wage determines profit through two channels only: directly through the wage bill and indirectly through its impact on the other firm's poaching. All the effects of the strategic wage on the firm's own poaching cancel out, since poaching is chosen at the following stage so as to maximize profit for any strategic wage.

$20 \frac{\partial^{2} R_{i}}{\partial \lambda_{i} \partial \beta}<0$ 
We can now outline the derivation of the sub-game equilibrium for this stage (a full derivation of the proposition below is given in Appendix 2). First, when the market is large, i.e., when the condition $\alpha \geq \bar{\alpha}$, whereby $\bar{\alpha} \equiv \frac{T(\beta)}{A B^{2}}-1$,

is satisfied, the maximization in equation (20) can be shown to imply that any maximum is such that $\omega_{1} \leq \underline{\underline{\omega}}$ and $\omega_{2} \leq \underline{\underline{\omega}}$. Thus, any pair $\left.\left(\omega_{1}, \omega_{2}\right) \leq \underline{\underline{\omega}}, \underline{\underline{\omega}}\right)$ is in equilibrium and leads to the poaching decisions: $\lambda_{1}^{*}\left(\omega_{1}, \omega_{2}\right)=\lambda_{2}^{*}\left(\omega_{2}, \omega_{1}\right)=1$. This defines a continuum of full poaching equilibria, $\Omega^{F P}$.

Second, for intermediate market size, i.e., when the condition $\underline{\alpha}<\alpha<\bar{\alpha}$, whereby

$$
\underline{\alpha} \equiv \frac{(F+D)^{2}(F-D)}{A B\left[(B+2 \beta) F^{2}+\left(2-\beta^{2}\right) D(F-D)\right]},
$$

is satisfied, the first-order conditions of program (20) for firms 1 and 2 can be shown to imply:

$$
\omega_{i}=\hat{\omega} \equiv \frac{\alpha A B\left((B+2 \beta) F^{2}+\left(2-\beta^{2}\right) D(F-D)\right)-(F+D)^{2}(F-D)}{F^{2}-D^{2} / 2+F\left(D-A \beta^{2} / 2\right)},
$$

where $\hat{\omega}>0$. This leads to the following poaching:

$$
\lambda_{i}^{*}(\hat{\omega}, \hat{\omega})=\hat{\lambda}(\hat{\omega}, \hat{\omega}) \equiv \hat{\lambda}=\frac{\alpha A B^{2} F+(F+D)(F-D)}{2 F^{2}-D^{2}+F\left(2 D-A \beta^{2}\right)},
$$

where $0<\hat{\lambda}<1$. We face here a second type of equilibrium for the sub-game. We call it partial poaching interior, $\Omega^{P P I}$. At this equilibrium, strategic wages are strictly positive and poaching is strictly between zero and one.

Finally, for small market size, i.e., when $\alpha \leq \underline{\alpha}$, the constraint $\omega_{i} \geq 0$ is binding, so that the solution of program (20) for firms 1 and 2 is $\omega_{1}=\omega_{2}=0$, and the corresponding (interior) poaching is:

$$
\lambda_{i}^{*}(0,0)=\lambda_{j}^{*}(0,0)=\frac{B D \alpha}{\beta(F+D)} .
$$

We speak here of a partial poaching corner equilibrium, $\Omega^{P P C}$, since poaching is positive and below unity with zero strategic wages. Last, it can be verified that if condition (SCE) is satisfied, so is the second-order condition at this stage. We obtain Proposition 2 (for which a complete proof is given in Appendix 2): 
Proposition 2. Under (SCE) and co-location, the sub-game perfect equilibria in Stage 2 are such that:

- $\Omega^{P P C}: \quad \omega_{1}^{*}=\omega_{2}^{*}=0$ and $\lambda_{1}^{*}=\lambda_{2}^{*}=B D \alpha /(\beta(F+D)), \quad$ if $\alpha \leq \underline{\alpha}$,

- $\Omega^{P P I}: \quad \omega_{1}^{*}=\omega_{2}^{*}=\hat{\omega}$ and $\lambda_{1}^{*}=\lambda_{2}^{*}=\hat{\lambda}, \quad$ if $\underline{\alpha}<\alpha<\bar{\alpha}$,

- $\Omega^{F P}: \quad\left\{\omega_{1}^{*} ; \omega_{2}^{*}\right\} \in[0 ; \underline{\underline{\omega}}]$ and $\lambda_{1}^{*}=\lambda_{2}^{*}=1, \quad$ if $\bar{\alpha} \leq \alpha$.

Note that the equilibrium is symmetric and unique for $\alpha<\bar{\alpha}$. In Figures 1 and 2 , these sub-game equilibria correspond to the origin, which is in region (vi) when $\alpha \leq \underline{\alpha}$, for $\Omega^{P P C}$, to a point on the bisecting line in region (vi) for $\Omega^{P P I}$, and to all the points in region (i) for $\Omega^{F P}$.

The intuitions for these results are the following. When market size $(\alpha)$ is small enough, rivalry is weak and firms do not attempt to prevent poaching, so that $\omega^{*}=0$ and $\lambda^{*}>0$. When $\alpha$ increases, so does $\lambda^{*}$, whereas $\omega^{*}$ remains zero until a first threshold $(\underline{\alpha})$ is met. Then, it becomes worthwhile for firms to raise their strategic wages to limit poaching due to increasing rivalry. As $\alpha$ keeps increasing, so do wages and poaching, until the feasibility constraint $\lambda^{*} \leq 1$ becomes binding. This defines a second threshold $\bar{\alpha}$, above which the poached firm is indifferent across all strategic wages which lead to full poaching by the other firm.

In the case of partial poaching interior equilibrium, $\Omega^{P P I}$ (i.e., $\underline{\alpha}<\alpha<\bar{\alpha}$ ), the comparative statics works as follows.

Proposition 3. Under (SCE) and co-location, when both poaching and strategic wages are interior:

- strategic wages increase with demand, $\partial \omega_{i}^{*} / \partial \alpha \geq 0$, and with the substitutability between products, $\partial \omega_{i}^{*} / \partial \beta \geq 0$, unless the cost of knowledge transmission sharply increases with $\beta$.

- poaching increases with demand, $\partial \lambda_{i}^{*} / \partial \alpha \geq 0$, but decreases with the substitutability between products, $\partial \lambda_{i}^{*} / \partial \beta \leq 0$, unless either $\alpha$ is low and the cost of knowledge transmission sharply decreases with $\beta$ or $\alpha$ is high and the cost of knowledge transmission sharply increases with $\beta$.

See Appendix 3 for a proof.

The comparative statics of equation (21) indicates that in absolute terms the negative revenue effect of more poaching by the other firm increases with market size and decreases with the degree of differentiation between products (the effect is stronger when both $\alpha$ and $\beta$ are high) ${ }^{2}$ This is because

$21 \frac{\partial^{2} R_{i}}{\partial \lambda_{j} \partial \alpha}<0$ and $\frac{\partial^{2} R_{i}}{\partial \lambda_{j} \partial \beta}<0$ 
differences in marginal costs between firms are relatively more important when demand is strong or when the degree of differentiation between products is low. Next, recall that firms gain from higher strategic wages because they discourage poaching by the other firm. This deterrent effect of strategic wages upon poaching does not depend on $\alpha$ and increases in absolute value with $\beta$ (the impact of higher strategic wages on poaching is larger when products are closer substitutes) 22 In sum, from a revenue perspective, firms have stronger incentives to increase their strategic wages when the demand and substitutability parameters are high.

Still from the comparative statics of equation (21), changes in $\alpha$ or $\beta$ also impact on the rise in costs caused by an increase in strategic wages. An increase in the size of the market reduces the number of non-poached workers (Proposition 1), and thus the corresponding cost. This goes in the same direction as the revenue effects described above. Consequently and without ambiguity, a higher demand increases the best-response in strategic wage. As regards $\beta$, the story is more intricate. From Proposition 1, poaching decreases when products become less differentiated provided $T($.$) is not too strongly decreasing in \beta$, which increases the number of retained workers. Moreover, the effect of strategic wages on poaching (the second term in the marginal cost of increasing $\omega_{i}$ in equation 21) increases with $\beta$, as just mentioned. Thus, an increase in $\beta$ increases both the gain and the costs of increasing $\omega_{i}$, which makes the total effect on the best-response ambiguous.

Furthermore, strategic wages in Stage 2 are strategic substitutes. Thus the indirect equilibrium effects are opposite to the direct ones that influence the best-responses. As a consequence, the impacts of $\alpha$ and $\beta$ on the equilibrium strategic wages are a priori ambiguous. However, Proposition 3 shows that strategic wages always increase with demand, $\alpha$. Strategic wages also increase with $\beta$ provided $T($.) does not increase too strongly. In this case, the direct rivalry and deterrent effects dominate the cost effects and the indirect effects. By contrast, when the cost of transferring knowledge strongly increases, poaching in Stage 3 strongly decreases with $\beta$, which reduces the incentives to increase strategic wages. Using strategic wages to further reduce poaching becomes less critical. Strategic wages may even decrease when products become more substitutes: the cost effect and the indirect effects dominate.

Regarding the impact of $\alpha$ and $\beta$ on the equilibrium number of poached workers, three effects play a role: the direct effect holding strategic wages constant at Stage 3 (See Proposition 1), and the two indirect effects working through strategic wages, which are detailed in the previous paragraphs and which act in opposite directions. First, market size has a positive effect on poaching: the direct effect of Stage 3 (poaching increases with $\alpha$ holding wages fixed) and the indirect effect due to the own strategic wage

$22 \frac{\partial^{2} \lambda_{j}^{*}}{\partial \omega_{i} \partial \alpha}=0$ and $\frac{\partial^{2} \lambda_{j}^{*}}{\partial \omega_{i} \partial \beta}<0$. 
( $\omega_{i}$ increases, which increases poaching) dominate the indirect effect going through the rival's wage $\left(\omega_{j}\right.$ increases, which decreases poaching). Turning to the inverse-degree of differentiation, $\beta$, the effects are again more intricate. In most cases, poaching decreases with $\beta$ : the direct effect of Stage 3 (poaching decreases with $\beta$ holding wages fixed) and the indirect effect going through the rival's wages $\left(\omega_{j}\right.$ increases, which decreases poaching) dominate the indirect effect due to the own strategic wage $\left(\omega_{i}\right.$ increases, which increases poaching). However, when $\alpha$ is low and the cost of transmitting knowledge, $T($.$) , strongly decreases, the direct effect is weak and poaching may even increase as stated in$ Proposition 1. Similarly, when $\alpha$ is high and $T($.) strongly increases, poaching and strategic wages are low and strategic wages increase less, and may even decrease with $\beta$. As a consequence, in these two specific cases, poaching increases with the substitutability between products.

\section{IV.4 SOME INTUITIONS WHEN (SCE) IS NOT VERIFIED}

In the $(\beta, T)$ space, condition (SCE) slopes upwards as $\beta$ increases and admits $\beta=1$ as vertical asymptote. The second-order conditions of Stages 2 and 3 also slope upwards with the same vertical asymptote. The second-order condition of Stage 2 lies between (SCE) and the second-order condition of Stage 3. Thus, for (SCE) to be satisfied for all $\beta \mathrm{s}$, we then need $T($.$) to be sufficiently increasing. When$ condition (SCE) is not satisfied, three different regions must be distinguished.

Immediately below (SCE), there is first a region where both second-order conditions for Stages 2 and 3 are satisfied. In this region, there are no particular difficulties as shown in Appendix 2. However, computations show that there is no sub-game equilibrium at Stage 2 in pure strategies for some values of $\alpha$. Non-existence arises here for the following reason. At the unique interior solution for strategic wages and poaching as derived from the first-order conditions, a firm can profitably deviate by lowering its strategic wage so that it no longer poaches anyone. This raises the firm's costs and lowers its market share but this loss is in some instances more than offset by a lower wage bill. Such a situation cannot be in equilibrium because this deviation gives the other firm an incentive to lower its wage as well.

Below, lies a second region where the second-order condition for Stage 3 is satisfied, whereas that for Stage 2 is not. Any equilibrium in pure strategies for the wage sub-game must thus be in a corner. However, neither symmetric nor asymmetric corner situations can in general be sustained as equilibria. In this region $\beta$ is large relative to $\alpha$ so that strong rivalry implies high strategic wages. These wages are so high as to make the deviation in strategic wages, $\omega=0$, profitable. The other corner situation with strategic wages equal to zero cannot be in equilibrium either. Because of strong rivalry, one firm is always tempted to raise its strategic wage to prevent poaching. Finally, no equilibrium can be sustained with asymmetric corner situations where one firm sets its wage to a low level and does not poach whereas the other sets its wage at a high enough level and poaches all the workers from the other firms. In this 
case, the former firm finds it profitable to raise its wage to reduce poaching by the latter. The bestresponse from this firm is then either to raise its wage further or to reduce it dramatically. Thus, there is no sub-game perfect equilibrium in pure strategies in this region. ${ }^{3}$

Even further below, lies the last region where both second-order conditions are not satisfied. For some parameter configurations, the solution of the poaching sub-game implies either full poaching or no poaching for both firms. This last situation can be shown never to be in equilibrium when solving the wage sub-game. For the other configurations, there is coexistence of two asymmetric equilibria involving full poaching for one firm and no poaching for the other. Thus, in this region, multiple sub-game equilibria are possible at Stage 3. This implies that the complete game can be solved only using game theory refinements and by studying mixed strategies, which is beyond the scope of this paper.

\section{LOCATION AND WELFARE ISSUES}

We can now turn to the location decision. When firms locate separately, they cannot poach due to the workers' immobility, which implies $\lambda_{1}^{*}=\lambda_{2}^{*}=0$. Thus, at Stage 2, they optimally set their strategic wages such that $\omega_{1}^{*}=\omega_{2}^{*}=0$. From (12) and (13), the firms' profit when they locate separately are:

$$
\pi_{1}^{S}=\pi_{2}^{S}=\pi^{S}=\frac{\alpha^{2}(1-\beta)}{(2-\beta)^{2}(1+\beta)} .
$$

\section{V.1 Stage 1: Location DeCision}

We can now define $\Phi(\alpha, \beta) \equiv \pi^{C}(\alpha, \beta)-\pi^{S}$ where $\pi^{C}$, the profit when firms co-locate, is either $\pi^{F P}$, $\pi^{P P I}$ or $\pi^{P P C}$ (i.e., the profits under the full-poaching, the partial-poaching interior or the partialpoaching corner equilibrium of Stage 2), depending on $\alpha$ and $\beta$. When $\Phi(\alpha, \beta) \geq 0$, firms want to colocate and two location equilibria are possible: $(I, I)$ and $(J, J)$. Both equilibria imply co-location. When $\Phi(\alpha, \beta)<0$, firms do not want to co-locate and two other location equilibria are possible: $(I, J)$ and $(J, I)$. Both equilibria imply dispersion.

We now turn to the determination of the sign of $\Phi(\alpha, \beta)$. For simplicity we assume that under fullpoaching, the firms' preferred equilibrium is played $\left(\omega_{1}^{*}=\omega_{2}^{*}=0\right)$. The results depend on the size of the market, the degree of differentiation between the products and the cost of transferring knowledge.

For a large market, that is when $\alpha \geq \bar{\alpha}$, which leads to the full-poaching equilibrium of Stage 2 , it can be

${ }^{23}$ This is a standard feature of Bertrand games with variable marginal costs. See Gabszewicz and Thisse (1999) for a general discussion on this issue. 
verified from equations (12), (13) (22) and (26) that:

$$
\Phi(\alpha, \beta)=2 A B^{2}(\alpha-\bar{\alpha}) \geq 0
$$

The profits of co-location are always higher than those of separation. Consequently the firms always colocate when the market is large.

For a market of intermediate size, that is when $\underline{\alpha}<\alpha<\bar{\alpha}$, which leads to the partial-poaching interior equilibrium of Stage 2, we obtain from Proposition 2 and equations (12), (13) and (26):

$$
\Phi(\alpha, \beta)=\frac{(2 \alpha+\hat{\lambda}) \hat{\lambda}(1-\beta)}{(2-\beta)^{2}(1+\beta)}-\hat{\omega}-T(\beta) \hat{\lambda}^{2} .
$$

Since from equations (24) and (25), $\hat{\lambda}$ and $\hat{\omega}$ are linear in $\alpha$, the expression $\Phi(\alpha, \beta)$ is quadratic in $\alpha$ with a positive coefficient for $\alpha^{2}$. The condition $\Phi(\alpha, \beta)=0$ can be shown to be either positive whatever $\alpha$ and $\beta$ or to have two positive $\alpha$-roots. In this latter case, both roots are either (i) greater than $\bar{\alpha}$, or (ii) only the smallest one is between $\underline{\alpha}$ and $\bar{\alpha}$, or (iii) both are between $\underline{\alpha}$ and $\bar{\alpha}$. Thus, three cases are possible: (i) the two firms always locate together, (ii) the two firms locate together for low $\alpha$ and separately for high $\alpha$, or (iii) the two firms locate together for low $\alpha$, separately for intermediate $\alpha$, and together again for high $\alpha$.

Finally, for a small market size, that is when $\alpha \leq \underline{\alpha}$, which leads to the partial poaching corner equilibrium of Stage 2, it is verified from Proposition 2 and equations (12), (13) (15), (17) and (26) that:

$$
\Phi(\alpha, \beta)=\frac{A^{2} B^{2}(B+\beta)(B F-\beta(F+D))}{(F+D)^{2}} \alpha^{2} .
$$

This expression is positive only when $\beta<\sqrt{3}-1$ and $T(\beta)\left(2-2 \beta-\beta^{2}\right) \geq A B^{2}\left(2-\beta^{2}\right)$, which does not depend on $\alpha$. Thus, when the market is small, the two firms co-locate only when $\beta$ is not too high, i.e., when the degree of differentiation is high enough and when the cost of transferring knowledge, $T(\beta)$, is large enough relatively to $\beta$. This leads to Proposition 4:

\section{Proposition 4. If (SCE) is satisfied and:}

- $\alpha \leq \underline{\alpha}$, the firms co-locate if and only if $T(\beta)$ is large enough relative to $\beta$,

- $\underline{\alpha}<\alpha<\bar{\alpha}$, the firms co-locate either for any $\alpha$, or only if $\alpha$ is close enough to $\alpha$, or for $\alpha$ close enough to both $\underline{\alpha}$ or to $\bar{\alpha}$, but not in between.

- $\bar{\alpha} \leq \alpha$, the firms always co-locate.

Hence the result we want emphasize in this paper is that firms can strategically decide to locate separately 
despite the lower unit labor requirements associated with a common location. The effects of market size, $\alpha$, as regards this possible outcome of separate locations, $\Omega^{S}$, are subtle. When $\alpha$ is below a first threshold $(\underline{\alpha})$, poaching increases with market size but strategic wages do not. Thus, there is clearly an incentive to co-locate when $\alpha \leq \underline{\alpha}$. Above this threshold, both poaching and wages increase with $\alpha$. A higher $\alpha$ then leads to both lower labor units costs and a higher wage bill. The overall effect on profit is ambiguous and can be non-monotonic as $\alpha$ increases: firms may not co-locate for high or intermediate values of $\alpha$. Then for a market larger than $\bar{\alpha}$, firms poach all of their strategic workers from each other. There is continuum of equilibria for the strategic wage but it makes sense for the firms to coordinate on the equilibrium with strategic wages equal to zero. This implies a low wage bill, large costs reduction and thus a strong incentive to co-locate.

The impact of products substituability on co-location cannot be determined without specifying the cost of transferring knowledge function $T($.$) , since the comparative statics on poaching and strategic wages$ depends on its slope in the Stage 2 sub-game. However, separate locations should occur when rivalry on the product market is strong ( $\beta$ close to 1 ), which is verified on both examples presented in section V.3. As stated in Proposition 3, strong rivalry induces both low poaching and high strategic wages, at least for $T($.) not too strongly increasing or decreasing. This implies that the costs of preventing others from poaching can be above the gains from poaching, when the differentiation between products is low, which leads firms to locate on different labor markets.

Another way to interpret these results is to think in terms of forces of agglomeration versus forces of dispersion. Our force of agglomeration is the opportunity for firms to improve their technology and lower their costs through the poaching of strategic workers from another firm. To our knowledge, this is a novelty with respect to the existing literature where the agglomeration forces are either driven by spillovers for which no microeconomic foundations are given or, when there is a labor market, by a better or safer matching between firms and workers. Our agglomeration force is strong when the costs of transferring knowledge are low (because of cheaper cost reductions), when the products are very differentiated (because firms can capture a large fraction of the surplus accruing from lower costs and because rivalry is weak) and when the market is large (because cost reduction takes place over a larger quantity of output). Our dispersion force stems from strategic interactions between rival firms who have incentives to push up their strategic wages to discourage the other firms from poaching from their workforce. This dispersion force is strong when the cost of transferring knowledge are low (because it makes poaching more attractive and thus forces firms to react by raising their wages), when differentiation between products is low (because the surplus accruing from lower costs goes to consumers and because higher rivalry results in higher wages to prevent poaching) and when market size is neither small nor big (because in both cases firms do not use strategic wages to prevent poaching either because the market is very small or because it would not prevent full poaching). When the dispersion force 
dominates the agglomeration force, firms prefer to locate separately.

\section{V.2 WELFARE}

We can now look at the welfare properties of our equilibria in order to state if all possible benefits of knowledge exchanges are captured or not. Total surplus is the sum of consumers', workers' and producers' surpluses:

$$
\begin{aligned}
T S & =(1+\alpha)\left(q_{1}+q_{2}\right)-\beta q_{1} q_{2}-\frac{1}{2}\left(q_{1}^{2}+q_{2}^{2}\right) \\
& -p_{1} q_{1}-p_{2} q_{2}+\left(1-\lambda_{1}\right) \omega_{2}+\lambda_{1} w_{1}+\left(1-\lambda_{2}\right) \omega_{1}+\lambda_{2} w_{2}+\pi_{1}+\pi_{2} .
\end{aligned}
$$

Proposition 5 is derived in Appendix 4:

\section{Proposition 5. The optimum implies at}

Stage 1: common location,

Stage 2: any strategic wages,

Stage 3: optimal poaching given by:

$$
\begin{array}{ll}
\text { - } \lambda_{1}^{* *}=\lambda_{2}^{* *}=\frac{\alpha}{2 T(\beta)(1+\beta)-1}, & \text { if } T(\beta)>\frac{1}{2\left(1-\beta^{2}\right)} \text { and } T(\beta)>\frac{\alpha+1}{2(1+\beta)}, \\
\text { - } \lambda_{1}^{* *}=1-\lambda_{2}^{* *}=0 \text { or } \lambda_{1}^{* *}=1-\lambda_{2}^{* *}=1, & \text { if } \frac{1}{2\left(1-\beta^{2}\right)} \geq T(\beta) \geq \frac{2(1-\beta) \alpha+1-2 \beta}{2\left(1-\beta^{2}\right)}, \\
\text { - } \lambda_{1}^{* *}=\lambda_{2}^{* *}=1, & \text { otherwise. }
\end{array}
$$

Stage 4: marginal cost pricing.

To avoid any deadweight loss, the optimum obviously involves marginal cost pricing. Since strategic wages only change the distribution of the surplus, they are irrelevant here. Furthermore, due to the costreduction arising from exchanging workers, the optimum also involves co-location. Regarding poaching, three cases are possible. When the costs of transferring knowledge are high, the optimum implies that not all strategic workers are exchanged. By contrast, when $T(\beta)$ is sufficiently small, the optimum involves full-poaching. When $T(\beta)$ is intermediate, a third case can arise. It involves an asymmetric costreduction whereby unit labor requirements do not change in one firm and are lowered as much as possible in the other. Asymmetric cost reduction is optimal when market demand is not large enough to justify the maximum cost reduction for both firms and when the two products are close enough substitutes that it makes sense to invest in only one product to avoid duplicating investment.

Turning now to the comparison between the optimum and the equilibrium, note first that, due to imperfect competition, the equilibrium price given by equation (9) is too high with respect to the optimum. Conditional on the firms co-locating, the poaching sub-game equilibrium may imply too much 
or too little poaching. This ambiguous outcome is the result of contradictory forces. First, equilibrium prices are above marginal costs. This reduces demand and thus the incentive for cost reduction. Second, firms raise the wage of their strategic workers. This makes poaching more costly - another force limiting cost reduction. However, there is also a rivalry effect whereby firms try to lower their costs relative to those of their competitors. This force pushes towards too much cost reduction - a frequent outcome in models of investments under market rivalry. Regarding location, firms' choices may also be sub-optimal in equilibrium. Having separate locations for firms in equilibrium is a very inefficient outcome since it prevents any form of poaching. Thus, the model predicts a tendency for sub-optimal dispersion.

\section{V.3 TWO EXAMPLES}

To sharpen the intuitions, it is worth exploring two examples for which $T($.$) is specified. As made clear$ above, the results depend on $T^{\prime}($.). We illustrate our results with the following two cases: $T(\beta)=1$ (the cost of knowledge transmission does not depend on the degree of differentiation between products) and $T(\beta)=1 /(1-\beta)$ (the closer substitutes the products are, the more difficult is the reduction of unit labor requirements by learning from rivals).

Consider first $T(\beta)=1$. Condition (SCE) can be shown to be satisfied for $\beta \leq \bar{\beta}$ with $\bar{\beta} \approx 0.83$. Applying Propositions 2 and 4, we can represent graphically the equilibrium depending on the two parameters $\alpha$ and $\beta$ (see Figure 3). ${ }^{4}$ Following Proposition 3, straightforward but tedious algebra shows that when the two firms share the same location, $\partial \lambda_{i}^{*} / \partial \alpha \geq 0, \partial \lambda_{i}^{*} / \partial \beta \leq 0, \partial \omega_{i}^{*} / \partial \alpha \geq 0$, and $\partial \omega_{i}^{*} / \partial \beta \geq 0$. Note also that firms tend to locate on separate labor markets only when the degree of differentiation is low enough (Proposition 4).

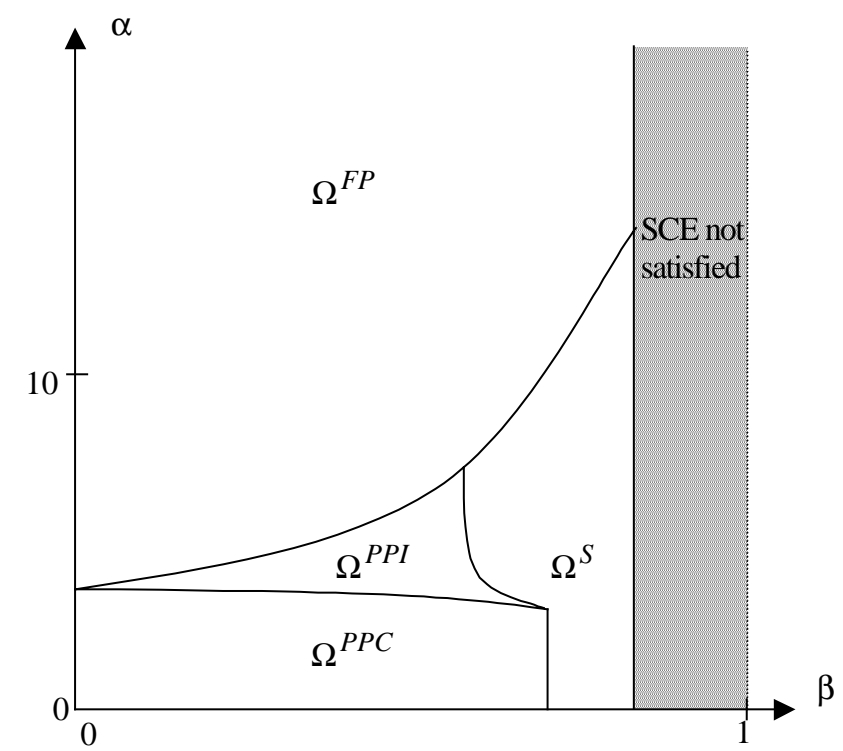

Figure 3.

\footnotetext{
${ }^{24}$ In the case of full poaching, we assume the firms' preferred equilibrium is chosen in both examples.
} 
The intuition for these results follows directly from Propositions 2 and 4. Due to the strategic and rivalry effects on the gross profit and on the wage bill, a larger market (a higher $\alpha$ ) raises the incentive to lower costs and thus to poach. Above a first threshold $(\underline{\alpha})$ and to counteract this, firms raise their strategic wages, which reduces poaching. These indirect effects are however not sufficient to cancel the direct one and poaching increases. If the substitutability between products is sufficiently high, profits under colocation may become lower than under separate locations when market size increases and firms choose different locations. Above a second threshold $(\bar{\alpha})$, there is full poaching and strategic wages go to zero, so that a common location is obtained whatever the market size and differentiation parameters.

An increase in $\beta$ makes strategic effects and rivalry stronger. This leads to higher wages and less poaching in equilibrium. In turn, this increase in $\beta$ reduces the incentive to co-locate. Thus, as products become closer substitutes, a common labor market becomes less attractive with a greater incentive to separate, and firms choose a common location only for $\beta$ low enough. Increased rivalry has a second effect. As $\beta$ increases, strategic wages may increase so much as to make a deviation profitable. For $\beta$ large enough, it is actually profitable for a firm not to try to retain its strategic workers and propose them very low strategic wages. There is no equilibrium in pure strategies in this case.

Regarding welfare, when firms locate separately, the equilibrium is sub-optimal. Optimal poaching would be strictly positive for these values of the parameters. Moreover, when firms locate in the same place, $\Omega^{F P}$ is optimal, but poaching is too low for both $\Omega^{P P I}$ and $\Omega^{P P C}$ because firms do not receive all the surplus created by lower marginal costs.

When $T(\beta)=1 /(1-\beta)$, the condition (SCE) is satisfied for any $\beta$. The equilibria, derived from Propositions 2 and 4, are represented in the $(\alpha, \beta)$ space in Figure 4. From Proposition 3, when the two firms share the same location, $\partial \lambda_{i}^{*} / \partial \alpha \geq 0, \partial \lambda_{i}^{*} / \partial \beta \leq 0, \partial \omega_{i}^{*} / \partial \alpha \geq 0$, and $\partial \omega_{i}^{*} / \partial \beta \leq 0$.

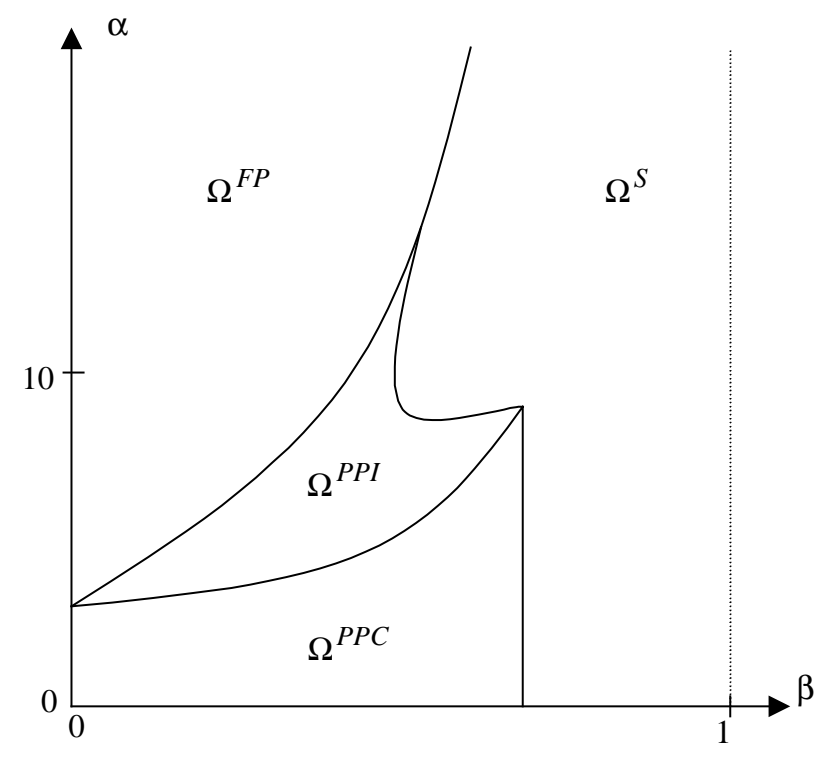

Figure 4. 
There are two major differences with the previous case: first, the equilibrium wage decreases with $\beta$ and, second, the equilibrium can be characterized for all parameter values. The reason for these differences lies in the fact that the costs of transferring knowledge, $T(\beta)$, increase with $\beta$. These rising costs of transferring knowledge more than offset the increase in the incentive to poach. Consequently, firms can lower the strategic wage they propose to their workers, while poaching simultaneously decreases. As a corollary, when $\beta$ increases, no opportunity for wage under-cutting arises and the existence of the subgame equilibrium is not called into question. Separate locations are still observed when the substituability between products is high and for intermediate demand size. Finally, the welfare results are the same as in the previous example.

\section{CONCLUSIONS}

To explore some of the issues raised by the labor market pooling argument, we proposed a model where firms, which ultimately compete on a differentiated product market, choose first a location. Then they hire workers that may later be poached by another firm if co-location arises, while they may themselves poach workers from the other firm. Anticipating this, firms may increase their wages to limit poaching. Our results show that co-location, although it is always efficient, is not in general the equilibrium outcome. In particular, it is when the conditions of perfect competition are approached that firms separate. As rivalry intensifies, poaching decreases while firms raise the wage of their strategic workers. This means a higher cost of co-location because of higher wages, as well as lower benefits from colocation because of smaller flows of workers and knowledge across firms. When the costs of poaching are higher than the benefits of pooling, firms choose to locate separately.

This model allows us to propose some alternative explanations regarding the functioning of some wellknown clusters, namely Silicon-Valley and Route 128. Saxenian (1994) attributes the success of the Valley and the relative decline of Route 128 to cultural differences between East and West in the US. In a nutshell, she claims that more open-minded Californians let their workforce hop from firm to firm, which yields important benefits for the Valley as a whole. By contrast, the 'culture' in the East is to try to retain workers as much as possible. Our model also accepts the premise that workers' mobility across firms is socially beneficial but it suggests a different explanation. Firms in Route 128 are mostly in the market for mainframes/mini-computers where the degree of differentiation is low, whereas software/internet activities, which dominate in the Valley, are intrinsically more differentiated (high $\beta$ versus low $\beta$ ). Furthermore, demand over the last 15 years has been much stronger in the software market than in the market for mini-computers (high $\alpha$ versus low $\alpha$ ). Consequently, in the light of our model, it may be optimal for firms in Route 128 to prevent poaching and for firms in the Valley not to prevent poaching.

Beyond this suggestive re-interpretation of a famous case, our model generates a set of predictions that may guide future empirical work. The first prediction is that wages for 'strategic' workers should be 
higher in areas where firms in the same industry cluster. ${ }^{25}$ Second, firms' productivity and productivity growth are predicted to increase with equilibrium workers' flows across firms ${ }^{26}$ Third, the model also predicts that the flows of workers between firms should be more important when firms cluster. Fourth, the comparative statics on market size also indicates that when a sector is booming, flows of workers across firms within the sector should be higher. Fifth, the comparative statics on product differentiation is less clear-cut but it nonetheless shows that the tendency for firms to cluster should increase with the degree of product differentiation within the industry. Sixth, like in human capital models, the wage is also predicted to increase steeply over time for key strategic workers ${ }^{27}$ This latter effect is not due to any form of general human capital accumulation, but on the contrary, it is caused by knowledge that one firm tries to protect and that others may obtain by hiring key workers. We hope these predictions will be subject to empirical scrutiny in the future.

A few unresolved issues and caveats are left for future theoretical work. Our model so far considers only two firms. The extension to many firms is important as a greater number of firms may change the terms of the trade-off between pooling and poaching. In particular the benefits to pooling may increase with the number of firms (more opportunities for firms to learn when there are more firms) whereas the cost of poaching may also decrease with the number of firms (through a dilution of the rivalry effect as workers leave to different firms). Second, alternative auctioning processes regarding strategic workers could be considered. For instance, one could think of using a simultaneous auction process where firms would decide how much to spend to retain strategic workers and to poach workers. A last important extension regards viewing the initial recruitment of strategic workers as an endogenous investment. This paper considers that only the diffusion of knowledge is endogenous, whereas of course it is both its generation and its diffusion that must ultimately be understood in the same framework.

\section{REFERENCES}

Abdel-Rahman H., AND Fujita M., 1990, "Product Variety, Marshallian Externalities, and City Sizes", Journal of Regional Science 30, 165-183.

ARROW K., 1962, "Economic Welfare and the Allocation of Resources for Invention " in R. R. Nelson

(ed) The Rate and Direction of Inventive Activity: Economic and Social Factors, National Bureau of Economic Research and Princeton University Press, 609-625.

BURDA M., AND WyPLOSZ C., 1994, "Gross Worker and Job Flows in Europe", European Economic

\footnotetext{
25 By contrast, the traditional insurance interpretation of labor market pooling implies that workers are happy to accept lower wages where there are more potential employers

${ }^{26}$ Davis and Haltiwanger (1998) indicate that a positive correlation between workers flows and productivity growth is observed in US data but the direction of causality remains unclear.

${ }^{27}$ See Møen (2000) for evidence on this point.
} 
Review 38, 1287-1315.

DAVIS S., AND HALTIWANGER J., 1998, "Measuring Gross Worker and Job Flows" in J. Haltiwanger , M. Manser and R. Topel (eds) Labor Statistics and Measurement Issues, National Bureau of Economic Research and University of Chicago Press, 77-119.

Duranton G., AND Puga D., 2000, "Diversity and Specialization in Cities: Why, Where and When Does it Matter?", Urban Studies 37, 533-555.

FRANCO A., AND FILSON D., 2000, "Knowledge Diffusion through Employee Mobility”, Federal Reserve Bank of Minneapolis, Staff report 272.

FuJITA M., AND Ogawa H., 1982, "Multiple Equilibria and Structural Transition of Non-monocentric Urban Configurations", Regional Science and Urban Economics 12, 161-196.

GABSZEWICZ J., AND THISSE J., 1999, "Introduction”, in Gabszewicz and Thisse (eds), Microeconomic Theories of Imperfect Competition, Classics in Economics, Edward Elgar, Cheltenham.

GreENwood M. J., 1997, "Internal Migration in Developed Countries" in M. Rosenberg and O. Stark (eds) Handbook of Population and Family Economics 1B, 647-720, North-Holland, Amsterdam.

HELSLEY R., AND STRANGE W, 1990, "Matching and Agglomeration Economies in a System of Cities", Regional Science and Urban Economics 20, 189-212.

Henry N., AND PINCH S., 1997a, "Motor Sport Valley: A Future Model of Regional Development?", School of Geography working paper 63, University of Birmingham.

HENRY N., AND PINCH S., 1997b, "A Regional Formula for Success?", mimeo University of Birmingham.

JACKSON T., 1997, Inside Intel, Harper Collins, London.

JACOBS J., 1969, The Economy of Cities, Harmondworth, NY.

JAFFE A., TRAJTEnBERG M., AND Henderson R., 1993, "Geographic Localization of Knowledge Spillovers as Evidenced by Patent Citations", Quarterly Journal of Economics 108, 577-598.

Jovanovic B., AND NyARKo Y., 1995, "The Transfer of Human Capital", Journal of Economic Dynamics and Control 19, 1033-1064.

Krugman P., 1991, Geography and Trade, MIT Press, Cambridge (Mass.).

LEAHY D., AND NeARY P., 1997, "Public Policy Towards R\&D in Oligopolistic Industries", American Economic Review 87, 642-662.

Marshall A., 1890, The Principles of Economics, McMillan (N.Y.), 1925.

MøEN J., 2000, “Is Mobility of Technical Personnel a Source of R\&D Spillovers?”, mimeo.

MotTA M., Fosfuri A., AND Rønde T., 2001, "Foreign Direct Investment and Spillovers through Workers' Mobility”, Journal of International Economics, forthcoming.

OtTAViano G., AND PUGA D., 1998, "Agglomeration in the global economy: A survey of the 'new economic geography", World Economy 21, 707-731.

Ottaviano G., AND Thisse J., 1999, "Monopolistic Competition, Multiproduct Firms and Optimum Product Diversity", Centre for Economic Policy Research Discussion Paper 2194. 
PAKES A., AND NitZAN S., 1983, "Optimum Contracts for Research Personnel, Research Employment, and the Establishment of Rival Enterprises", Journal of Labor Economics 1, 345-365.

PINCH S., Henry N., AND TuRner D., 1997, "In Pole Position: Explaining the Supremacy of Britain's Motor Sport Valley", School of Geography working paper 62, University of Birmingham.

RoSEN S., 1972, "Learning and Experience in the labor market", Journal of Human Resources 7, 326342.

SAXENIAN A., 1994, Regional Advantage, Harvard University Press.

TIROLE, J., 1988, The Theory of Industrial Organization, MIT Press.

\section{APPENDIX 1: ProOf OF Proposition 1}

When (SCE) is satisfied, $B, F, D$ and $(F-D)$ are positive and do not depend on $\alpha$. The comparative statics of poaching with respect to $\alpha, \omega_{i}$ and $\omega_{j}$ is thus directly obtained from equations (18) and (19) which give poaching at Stage 3 for region (vi) and regions (ii) and (iv), respectively. In the other regions, poaching is constant. Turning to the comparative statics of poaching with respect to $\beta$ in the symmetric case $\left(\omega_{i}=\omega_{j}=\omega\right)$, note that equation (18) reduces to:

$$
\hat{\lambda}\left(\omega_{i}, \omega_{j}\right) \equiv \frac{1}{F+D}\left(\frac{B D}{\beta} \alpha-\omega\right)
$$

From the definition of $F$, we have:

$$
\frac{\partial\left(\frac{1}{F+D}\right)}{\partial \beta}=-\frac{T^{\prime}(\beta)-\frac{\partial\left(A(B+\beta)^{2}\right)}{\partial \beta}+\frac{\partial D}{\partial \beta}}{(F+D)^{2}},
$$

where $-\partial\left(A(B+\beta)^{2}\right) / \partial \beta+\partial D / \partial \beta>0$. Thus, as long as $T($.$) is not too strongly decreasing in \beta$, $\partial\left(\frac{1}{F+D}\right) / \partial \beta \leq 0$. Since $B D / \beta$ also decreases with $\beta$, the number of poached workers decreases with $\beta$ in this case. A strong decrease of $T($.$) with \beta$ may on the contrary induce an increase in $1 /(F+D)$ that offsets the decrease of $B D / \beta$, in which case poaching may increase with $\beta$.

\section{APPENDIX 2: PROOF OF PROPOSITION 2}

In this proof, we loosely use the term "equilibrium" for "sub-game perfect equilibrium in pure strategies in Stage 2". Let us proceed in steps.

Step 0. When (SCE) is satisfied, $\underline{\omega}\left(\omega_{1}\right)$ (resp. $\bar{\omega}\left(\omega_{1}\right)$ ) is strictly increasing and strictly less steep than 
$\underline{\omega}\left(\omega_{2}\right)$ (resp. $\left.\bar{\omega}\left(\omega_{2}\right)\right)$ in the $\left(\omega_{1}, \omega_{2}\right)$ space (as drawn in Figures 1 and 2 ).

Simple computations show that $\underline{\omega}\left(\omega_{1}\right)$ and. $\bar{\omega}\left(\omega_{1}\right)$ are strictly increasing if $D / F>0$. The conditions $\underline{\omega}\left(\omega_{1}\right)$ less steep than $\underline{\omega}\left(\omega_{2}\right)$ and $\bar{\omega}\left(\omega_{1}\right)$ less steep than $\bar{\omega}\left(\omega_{2}\right)$ in the $\left(\omega_{1}, \omega_{2}\right)$ space reduce to $\left(F^{2}-D^{2}\right) / F D \geq 0$. It is then easy to show that these two conditions are satisfied when (SCE) holds.

Step 1. There is no equilibrium in regions (iii), (iv) or (v).

From Lemma 2, we have $\lambda_{j}^{*}\left(\omega_{j}, \omega_{i}\right)=0$ in regions (iii), (iv) or (v) so that firm $i$ 's profit is equal to:

$\pi_{i}=A\left[\alpha B+\left(2-\beta^{2}\right) \lambda_{i}^{*}\left(\omega_{i}, \omega_{j}\right)\right]^{2}-\omega_{i}-\omega_{j} \lambda_{i}^{*}\left(\omega_{i}, \omega_{j}\right)-T(\beta) \lambda_{i}^{*}\left(\omega_{i}, \omega_{j}\right)^{2}$,

with $\partial \lambda_{i}^{*}\left(\omega_{i}, \omega_{j}\right) / \partial \omega_{i}=0$ in these regions (Lemma 2). It is then straightforward that $\partial \pi_{i} / \partial \omega_{i}<0$, which prevents the existence of any equilibrium in these regions.

Step 2. There is a unique equilibrium in region (vi) for a non-empty set of parameters $(\underline{\alpha}<\alpha<\bar{\alpha})$ and it is symmetric.

Step 2.1. (SCE) implies that the second order conditions of both Stages 2 and 3 are satisfied.

Program (20), evaluated at $\lambda_{1}^{*}\left(\omega_{1}, \omega_{2}\right)=\hat{\lambda}\left(\omega_{1}, \omega_{2}\right)$ and $\lambda_{2}^{*}\left(\omega_{1}, \omega_{2}\right)=\hat{\lambda}\left(\omega_{2}, \omega_{1}\right)$ leads to the bestresponses:

$$
\begin{aligned}
& \omega_{i}^{B R}\left(\omega_{j}\right)=\frac{-2(F+D)^{2}\left(F-A \beta\left(4-2 \beta-\beta^{2}\right)\right)^{2}-A \beta^{2} D T(\beta) \omega_{j}}{F\left(2 F^{2}-\beta^{2} A F-3 D^{2}\right)} \\
& +\frac{(F-D)\left(F^{2}+A F\left(4-\beta-6 \beta^{2}+2 \beta^{4}\right)-A^{2}(B+\beta)^{2}\left(4-\beta-2 \beta^{2}+\beta^{3}\right)\right)^{2} \alpha}{F\left(2 F^{2}-\beta^{2} A F-3 D^{2}\right)}
\end{aligned}
$$

assuming that the second-order condition, which reduces to $2 F^{2}-\beta^{2} A F-3 D^{2}>0$, holds. Since this inequality holds whenever (SCE) is satisfied, the second-order conditions of Stages 2 and 3 are satisfied. Note also that under (SCE), firm $i$ 's best-response regarding its strategic wage is decreasing with firm $j$ 's strategic wage.

Step 2.2. In region (vi), there is a unique and symmetric equilibrium candidate.

Since the second-order conditions are satisfied, any equilibrium in region (vi) is given by the intersection of the best-responses (A4) of the two firms. This intersection is unique since these conditions are linear in $\left(\omega_{1}, \omega_{2}\right)$. It is also symmetric. Straightforward computations show that this candidate, $\Omega^{P P I}$ (for Partial Poaching Interior equilibrium), is defined by $\omega_{1}^{*}=\omega_{2}^{*}=\hat{\omega}$ and $\lambda_{1}^{*}=\lambda_{2}^{*}=\hat{\lambda}$ with $\hat{\omega}$ and $\hat{\lambda}$ given in equations (24) and (25) of the main text. $\Omega^{P P I}$ is in interior equilibrium if and only if $0<\hat{\lambda}<1, \hat{\omega}>0$, 
and if no firm, by changing $\omega_{i}$, can profitably deviate to another region. Steps 2.3 and 2.4 check these conditions.

Step 2.3. The existence conditions $0<\hat{\lambda}<1$ and $\hat{\omega}>0$, reduce to $\underline{\alpha}<\alpha<\bar{\alpha}$, where $\underline{\alpha}$ and $\bar{\alpha}$ depend only on $T($.$) and \beta$.

Straightforward computations show that the condition $\hat{\lambda}>0$ is always verified. Moreover, the condition $\hat{\lambda}<1$ reduces to $\alpha<\bar{\alpha}$ with $\bar{\alpha}$ defined in equation (22) of the main text. Similarly, the condition $\hat{\omega}>0$ reduces to $\underline{\alpha}<\alpha$ with $\underline{\alpha}$ defined in equation (23) of the main text.

Step 2.4. No firm can profitably deviate from $\Omega^{P P I}$ to another region $\underline{\alpha}<\alpha<\bar{\alpha}$.

a) From step 0, no unilateral deviation from region (vi) can take place in regions (i) and (v).

b) We check now that no firm $i$ can choose $\omega_{i}$ so as to profitably switch to region (ii).

- Firm $i$ cannot profitably deviate in the part of region (ii) where $\omega_{i}<\omega_{j}$. Since firm $j$ poaches all its strategic workers, its profit does not depend on $\omega_{i}$ in this region and it is equal to the profit obtained at $\underline{\omega}\left(\omega_{j}\right)$. By continuity, this is equal to the profit when $\omega_{i}$ tend towards this line in region (vi). This profit is however lower than the maximized profit in region (vi), at the equilibrium candidate $\Omega^{P P I}$.

- In the part of region (ii) where $\omega_{i}>\omega_{j}$, it can be shown that firm $i$ 's profit is concave in $\omega_{i}$. For any $\omega_{j}$, the strategic wage that satisfies the first-order condition of profit maximization in this region is given by:

$\omega_{i}=\hat{\omega}^{d} \equiv \frac{2 \alpha A B(F(B+2 \beta)-\beta D)-2 F^{2}+2 A D \beta^{2}}{2 F-A \beta^{2}}$.

A necessary condition for the deviation to be profitable is $\underline{\omega}^{-1}(\hat{\omega}) \leq \hat{\omega}^{d}$. Simple computations show that this condition implies $\bar{\alpha} \leq \alpha$, which is impossible from step 2.2 since $\Omega^{P P I}$ exists only when $\underline{\alpha}<\alpha<\bar{\alpha}$. c) It remains to show that no deviation to region (iv) is profitable. The proof is similar to that for region (ii).

- Firm $i$ cannot profitably deviate in the part of region (iv) where $\omega_{j}<\omega_{i}$. By the same arguments as used in step 1, firm $i$ 's profit strictly decreases with its wage in the part of region (iv) where $\omega_{j}<\omega_{i}$. By continuity, it is thus lower than the profit firm $i$ obtains in region (vi) at $\bar{\omega}\left(\omega_{j}\right)$. This profit is however lower than the maximized profit for the region (vi) at the equilibrium candidate $\Omega^{P P I}$.

- Turning to the part of region (iv) where $\omega_{j}>\omega_{i}$, it can be shown that firm i's profit is concave in $\omega_{i}$. For any $\omega_{j}$, the strategic wage that satisfies the first-order condition of profit maximization in this region 
is given by:

$\omega_{i}=\hat{\omega}^{d d} \equiv \frac{2 A B(F(B+2 \beta)-\beta D) \alpha-2 F^{2}}{2 F-A \beta^{2}}$.

Note that $\hat{\omega}^{d d}$ is not necessarily positive when (SCE) is satisfied. When $\hat{\omega}^{d d} \leq 0$, the strategic wage for firm $i$ when deviating is 0 .

d) However, the pair $\left(\operatorname{Max}\left(\hat{\omega}^{d d}, 0\right), \hat{\omega}\right)$ does not necessarily belong to region (iv). A necessary condition for firm $i$ to profitably deviate is to have $\operatorname{Max}\left(\hat{\omega}^{d d}, 0\right) \leq \bar{\omega}^{-1}(\hat{\omega})$. Some computations show that this condition is equivalent to $\alpha \leq \overline{\bar{\alpha}}$, where $\overline{\bar{\alpha}}$ is a function of $\beta$ and $T$. When (SCE) is satisfied, $\bar{\alpha}<\underline{\alpha}$ so that no profitable deviation can occur when $\alpha \leq \underline{\alpha}$.

e) When (SCE) is satisfied, we just proved that no deviation to region (iv) is profitable, thus no deviation to region (iii) is profitable either, since firm $i$ 's profit does not depend on $\omega_{j}$ in region (iii), and is equal, by continuity, to the profit it obtains in region (iv) when $\omega_{i}$ tends towards $\underline{\omega}$.

a), b), c), d) and e) guarantee that no deviation is profitable from $\Omega^{P P I}$ to any other region when $\underline{\alpha}<\alpha<\bar{\alpha}$. Finally, this region is never empty since it is easy to show that $\underline{\alpha}<\bar{\alpha}$.

Step 3. There is a unique symmetric corner equilibrium when $\alpha \leq \underline{\alpha}$.

Clearly, if $\alpha \leq \underline{\alpha}$, that is if $\hat{\omega} \leq 0$, simple calculations show that there is an equilibrium candidate $\Omega^{P P C}$ (for Partial Poaching Corner equilibrium) with $\omega_{1}^{*}=\omega_{2}^{*}=0$ and $\lambda_{1}^{*}=\lambda_{2}^{*}=B D \alpha /(\beta(F+D)$ ) (which is obtained by inserting $\omega_{1}^{*}=\omega_{2}^{*}=0$ in the definition of the equilibrium candidate for region (vi) given in Lemma 2). Note that $\alpha \leq \underline{\alpha}$ guarantees $0<\lambda_{i}^{*}<1$. Moreover, from step 2.3, we also know that no firm can profitably deviate by changing its strategic wage. Thus, $\alpha \leq \underline{\alpha}$ ensures that $\Omega^{P P C}$ is in equilibrium.

Step 4. There is a continuum of equilibria in region (i) for a non-empty set of parameters.

Step 4.1. Any point in region (i) is an equilibrium candidate.

First note that region (i) is feasible (strategic wages are non-negative) if and only if $0 \leq \underline{\underline{\omega}}$. When this condition is satisfied, any point in region (i) may be in equilibrium, since the profit of any firm does not depend on its strategic wage (all workers are poached). Let $\Omega^{F P}$ (for Full Poaching equilibrium) denote one of these equilibrium candidates where $\omega_{1}^{*} \in[0, \underline{\underline{\omega}}], \omega_{2}^{*} \in[0, \underline{\underline{\omega}}]$ and $\lambda_{1}^{*}=\lambda_{2}^{*}=0$.

Step 4.2. No firm can profitably deviate from $\Omega^{F P}$ to another region when $\bar{\alpha} \leq \alpha$.

a) From step 0, no unilateral deviation from region (i) can take place in regions (iv), (v) and (vi). 
b) By the argument used in step 1, no firm would find profitable to switch to region (iii), if we prove that it is not profitable to switch to region (ii). Thus, we just have to check possible profitable deviations to region (ii).

c) Firm $i$ can only deviate in the part of region (ii) where $\omega_{j}<\omega_{i}$. As in step 2, in this region, firm $i$ 's strategy is given by (A4). A necessary condition for firm $i$ to profitably deviate from $\Omega^{F P}$ to region (ii) is thus $\underline{\underline{\omega}}<\hat{\omega}^{d}$. Direct computations show that this condition is equivalent to $\alpha<\bar{\alpha}$. Thus, there is no profitable deviation when $\bar{\alpha} \leq \alpha$.

d) It can be checked that when $\bar{\alpha} \leq \alpha$, then $0<\underline{\underline{\omega}}$. This proves that region (i) is not empty in this case.

From a), b), c) and d), we can conclude that a continuum of full poaching equilibria exists in region (i), which is not an empty set when $\bar{\alpha} \leq \alpha$.

Step 5. There is no equilibrium in region (ii).

It is sufficient to prove that at least one firm deviates from any point belonging to region (ii) that we decompose in the part where $\bar{\alpha} \leq \alpha$ and the one where $\alpha<\bar{\alpha}$.

Step 5.1. There is no equilibrium in region (ii) where $\omega_{j} \leq \omega_{i}$, when $\bar{\alpha} \leq \alpha$.

In step 4.2, it has been observed that $\hat{\omega}^{d} \leq \underline{\underline{\omega}}$ when $\bar{\alpha} \leq \alpha$. Thus, when $\bar{\alpha} \leq \alpha$, firm $i$ can profitably deviate to either region (i) (when $\omega_{j} \leq \underline{\underline{\omega}}$ ) or region (vi) (when $\underline{\underline{\omega}}<\omega_{j}$ ).

Step 5.2. There is no equilibrium in region (ii) where $\omega_{j} \leq \omega_{i}$, when $\alpha<\bar{\alpha}$.

For any $\omega_{i}$ such that $\underline{\underline{\omega}} \leq \omega_{i} \leq \underline{\omega}$ in region (ii), firm $j$ 's profit does not depend on $\omega_{j}$, since firm $i$ poaches all its labor force, whatever $\omega_{j}$. By continuity, this profit is equal to the profit firm $j$ obtains in region (vi) at $\left(\omega_{i}, \underline{\omega}\left(\omega_{i}\right)\right)$. If at this point, firm $j$ 's profit increases with $\omega_{j}$, firm $j$ profitably deviate to region (vi). However marginal profit is not necessarily positive, even when $\Omega^{P P I}$ exists (when $\alpha<\bar{\alpha}$ ): firm $j$ 's best-response is decreasing, but its intersection with $\underline{\omega}\left(\omega_{j}\right)$ could be below $\left(\omega_{i}, \underline{\omega}\left(\omega_{i}\right)\right)$. However, simple computations show that the derivative of firm $j$ 's profit in $\left(\omega_{i}, \underline{\omega}\left(\omega_{i}\right)\right)$ is indeed positive when $\alpha<\bar{\alpha}$.

These five steps lead to Proposition 1.

\section{APPENDix 3: Proof of Proposition 3}

From equation (24) and (25), the poaching and strategic wage in equilibrium $\Omega^{P P I}$ can be written as:

$\omega_{i}=\hat{\omega}=\frac{H+\alpha K}{L} \quad$ and $\quad \lambda_{i}=\hat{\lambda}=\frac{M+\alpha N}{2 L}$ 
with $H=-(F+D)^{2}(F-D), K=A B\left((B+2 \beta) F^{2}+\left(2-\beta^{2}\right) D(F-D)\right), L=F^{2}-D^{2} / 2+F\left(D-A \beta^{2} / 2\right)$, $M=(F+D)(F-D), N=A B^{2} F$.

Straightforward computations show that $K, L$ and $N$ are positive, which implies that both strategic wages and poaching increase with $\alpha$. Regarding $\beta$, we have:

$$
\frac{\partial \hat{\omega}}{\partial \beta}=\frac{1}{L^{2}}\left(\frac{\partial H}{\partial \beta} L-H \frac{\partial L}{\partial \beta}+\alpha\left(\frac{\partial K}{\partial \beta} L-K \frac{\partial L}{\partial \beta}\right)+T^{\prime}(\beta)\left(\frac{\partial H}{\partial T} L-H \frac{\partial L}{\partial T}+\alpha\left(\frac{\partial K}{\partial T} L-K \frac{\partial L}{\partial T}\right)\right)\right)
$$

It is easy to show that: $L \partial H / \partial \beta-H \partial L / \partial \beta>0$. When $L \partial K / \partial \beta-K \partial L / \partial \beta \geq 0$, this implies:

$$
\frac{\partial H}{\partial \beta} L-H \frac{\partial L}{\partial \beta}+\alpha\left(\frac{\partial K}{\partial \beta} L-K \frac{\partial L}{\partial \beta}\right) \geq 0
$$

When $L \partial K / \partial \beta-K \partial L / \partial \beta<0$, using the fact that $\hat{\lambda} \leq 1 \Leftrightarrow \alpha \leq(2 L-M) / N$, we have:

$$
\frac{\partial H}{\partial \beta} L-H \frac{\partial L}{\partial \beta}+\alpha\left(\frac{\partial K}{\partial \beta} L-K \frac{\partial L}{\partial \beta}\right) \geq \frac{\partial H}{\partial \beta} L-H \frac{\partial L}{\partial \beta}+\frac{2 L-M}{N}\left(\frac{\partial K}{\partial \beta} L-K \frac{\partial L}{\partial \beta}\right)>0
$$

Similarly, $L \partial H / \partial T-H \partial L / \partial T<0$, but $L \partial K / \partial T-K \partial L / \partial T>0$. Using $\hat{\lambda} \leq 1 \Leftrightarrow \alpha \leq(2 L-M) / N$, this implies:

$$
\frac{\partial H}{\partial T} L-H \frac{\partial L}{\partial T}+\alpha\left(\frac{\partial K}{\partial T} L-K \frac{\partial L}{\partial T}\right) \leq \frac{\partial H}{\partial T} L-H \frac{\partial L}{\partial T}+\frac{2 L-M}{N}\left(\frac{\partial K}{\partial T} L-K \frac{\partial L}{\partial T}\right)<0
$$

Thus, when $T^{\prime}() \leq$.0 or when $T($.) is not too strongly increasing, (A8)-(A11) imply: $\partial \hat{\omega} / \partial \beta \geq 0$.

Turning to poaching, from (A7), we have:

$$
\frac{\partial \hat{\lambda}}{\partial \beta}=\frac{1}{L^{2}}\left(\frac{\partial M}{\partial \beta} L-M \frac{\partial L}{\partial \beta}+\alpha\left(\frac{\partial N}{\partial \beta} L-N \frac{\partial L}{\partial \beta}\right)+T^{\prime}(\beta)\left(\frac{\partial M}{\partial T} L-M \frac{\partial L}{\partial T}+\alpha\left(\frac{\partial N}{\partial T} L-N \frac{\partial L}{\partial T}\right)\right)\right)
$$

Using a comparable majoration than for (A13), we obtain:

$$
\frac{\partial M}{\partial \beta} L-M \frac{\partial L}{\partial \beta}+\alpha\left(\frac{\partial N}{\partial \beta} L-N \frac{\partial L}{\partial \beta}\right) \leq \frac{\partial M}{\partial \beta} L-M \frac{\partial L}{\partial \beta}+\frac{2 L-M}{N}\left(\frac{\partial N}{\partial \beta} L-N \frac{\partial L}{\partial \beta}\right)<0
$$

However, regarding the second term, we have: $L \partial M / \partial T-M \partial L / \partial T>0$, but $L \partial N / \partial T-N \partial L / \partial T<0$, and no majoration or minoration can be obtained for $L \partial M / \partial T-M \partial L / \partial T+\alpha(L \partial N / \partial T-N \partial L / \partial T)$. This expression is positive for low $\alpha$ and negative when $\alpha$ is high. The comparative statics on poaching with respect to $\beta$ is directly obtained from this.

\section{ApPendix 4: Proof of Proposition 5}

Using (1), (3), (4), (5), (7), total surplus can be simplified into:

$$
T S=(1+\alpha)\left(q_{1}+q_{2}\right)+\beta q_{1} q_{2}-\frac{1}{2}\left(q_{1}^{2}+q_{2}^{2}\right)-\left(1-\lambda_{1}\right) q_{1}-\left(1-\lambda_{2}\right) q_{2}-T(\beta)\left(\lambda_{1}^{2}+\lambda_{2}^{2}\right) .
$$

The sufficient first-order conditions in $q_{1}$ and $q_{2}$ imply: 


$$
q_{i}=\frac{1+\alpha}{1+\beta}+\frac{\beta}{1-\beta^{2}}\left(1-\lambda_{j}\right)-\frac{1}{1-\beta^{2}}\left(1-\lambda_{i}\right) .
$$

It is immediate that (A15) is equivalent to marginal cost pricing. Insert (A15) into (A14) and take the first-order conditions with respect to $\lambda_{i}$ to get:

$$
\frac{\partial T S}{\partial \lambda_{i}}=\frac{\alpha}{1+\beta}-\frac{\beta}{1-\beta^{2}} \lambda_{j}+\frac{1-2 T(\beta)\left(1-\beta^{2}\right)}{1-\beta^{2}} \lambda_{i}
$$

If $2 T(\beta)\left(1-\beta^{2}\right)>1$, the first-order conditions are sufficient to define a global maximum and we find $\lambda_{1}^{* *}=\lambda_{2}^{* *}=\operatorname{Max}(1, \alpha /(2 T(1+\beta)-1))$. When $2 T(\beta)\left(1-\beta^{2}\right) \leq 1$, the first-order conditions no longer define a global maximum. The optimum must be a corner solution. The case $\lambda_{1}=\lambda_{2}=0$ must be ruled out because of (A14). $\lambda_{i}=1-\lambda_{j}=0$ can be shown to be a local maximum when $\alpha \leq \beta /(1-\beta)$. Further, it can be checked that $\lambda_{1}=\lambda_{2}=1$ is a maximum when $\alpha \geq\left(\beta-1+2 T(\beta)\left(1-\beta^{2}\right)\right) /(1-\beta)$. The comparison of these two local maxima implies that $\lambda_{1}=\lambda_{2}=1$ is a global maximum when $\alpha>\frac{2 \beta-1+2 T\left(1-\beta^{2}\right)}{2(1-\beta)}$.

Finally regarding Stage 1, it is immediate that at the optimum the two firms must be located in the same labor market. These results are summarized in Proposition 5. 